\title{
Solubilisation of model membrane by DDAO surfactant - partitioning, permeabilisation and liposome-micelle transition
}

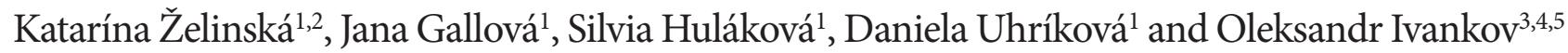 \\ ${ }^{1}$ Department of Physical Chemistry of Drugs, Faculty of Pharmacy, Comenius University in Bratislava, Bratislava, Slovakia \\ 2 Institut Laue-Langevin, Grenoble, France \\ ${ }^{3}$ Frank Laboratory of Neutron Physics, Joint Institute for Nuclear Research, Dubna, Russia \\ ${ }^{4}$ Moscow Institute of Physics and Technology, MIPT, Dolgoprudny, Russia \\ ${ }^{5}$ Institute for Safety Problems of Nuclear Power Plants, NAS Ukraine, Kiev, Ukraine
}

Dedicated to prof. P. Balgavý on the occasion of his 75th birthday.

\begin{abstract}
Solubilisation of model membranes of dioleoylphosphatidylcholine (DOPC) and DOPCcholesterol (CHOL) induced by surfactant $N, N$-dimethyl-1-dodecanamine- $N$-oxide (DDAO) was studied. At the maintained $\mathrm{pH} \sim 7.5$, the DDAO molecules are in their neutral state with respect to the $\mathrm{pK} \sim 5$. Pore formation in lipid bilayer was studied by fluorescence probe leakage method. The changes in the size of lipid aggregates upon increasing DDAO concentration were followed turbidimetrically. Effective ratio $R_{e}$ at different steps of the solubilisation process was determined. The molar partition coefficient of DDAO in case of the DOPC membrane is $K_{p}=2262 \pm 379$, for DOPC-CHOL membrane $K_{p}=2092 \pm 594$. Within the experimental error, the partition coefficient, as well as effective ratios $R_{e}$, are not considerably influenced when one third of DOPC molecules is substituted with CHOL (DOPC:CHOL $=2: 1$ ). Constituents of buffer $\left(50 \mathrm{mmol} / \mathrm{dm}^{3} \mathrm{PBS}, 150 \mathrm{mmol} /\right.$ $\mathrm{dm}^{3} \mathrm{NaCl}$ ) caused aggregation of DOPC and DOPC-CHOL unilamellar liposomes at zero and low DDAO concentration, as was shown by SANS, turbidimetry and DIC microscopy. After solubilisation of bilayer structures by surfactant, mixed DOPC-DDAO and DOPC-CHOL-DDAO micelles with the shape of cylinders with elliptical cross section were detected.
\end{abstract}

Key words: $N, N$-dimethyl-1-dodecanamine- $N$-oxide — Dioleoylphosphatidylcholine - Cholesterol - Partition coefficient - Solubilisation

Abbreviations: CHOL, cholesterol; DDAO, N,N-dimethyl-1-dodecanamine- $N$-oxide; DOPC, dio-
leoylphosphatidylcholine; EYPC, egg yolk phosphatidylcholine; MLLs, multilamellar liposomes;
PBS, phosphate buffered saline; SANS, small-angle neutron scattering; ULLs, unilamellar liposomes.

\section{Introduction}

$N, N$-dimethyl-1-dodecanamine- $N$-oxide (DDAO) is an amphiphilic molecule occurring in its non-ionic form at physiological pH (Herrmann 1962; Búcsi et al. 2014).

Correspondence to: Katarína Želinská, Department of Physical Chemistry of Drugs, Faculty of Pharmacy, Comenius University in Bratislava, Odbojárov 10, 83232 Bratislava, Slovakia E-mail: zelinska@fpharm.uniba.sk
DDAO possess a wide range of biological effects, e.g. antimicrobial activity (Devínsky et al. 1990), phytotoxic (Šeršeň et al. 1992), antiphotosynthetic (Murín et al. 1990) and immunomodulatory (Bukovský et al. 1996; Kacáni et al. 1996) effect. In spite of its effects, DDAO is a common additive of commercially used products of daily use, such as dishwashing liquids and surface cleaners, cosmetics and pharmaceutical formulations etc. (see Singh et al. 2006 for a review). As declared in the report of Japan Soap and Detergent Association (JSDA, Tokyo, Japan), environmentally 
relevant concentrations are lower than 10-70 ng/l (detected in some Japanese rivers). It is unlikely that DDAO exerts toxic actions on wild animals and humans at this concentration (cited in Fukunaga et al. 2014 and references therein). Nevertheless, further monitoring is needed. DDAO is also widely used in membrane and protein studies as a mild surfactant for solubilisation of membranes and for purification, reconstitution and crystallization of membrane proteins (le Maire et al. 2000; Rigaud et al. 2000; Alonso and Roujeinikova 2012).

DDAO interacts mostly with phospholipid bilayers in protein-containing membranes (Kragh-Hansen et al. 1998). For the interaction studies of molecules affecting the lipid parts of bio-membranes, phospholipid bilayers are used as simplified models of the membrane. DDAO molecules intercalate into the phospholipid bilayer due to their amphiphilic character. Its polar fragment (strong polar N-O bond) is localised near to the polar fragments of phospholipid molecules and the twelve-carbon hydrophobic chain is parallel to the phospholipid hydrocarbon chains. Our group studied the influence of DDAO on the structure of lipid bilayers using various methods. Densitometry study (Belička et al. 2014a) of dioleoylphosphatidylcholine (DOPC) mixtures with $N, N$ dimethyl-1-alkylamine- $N$-oxides (including DDAO) proved ideal mixing of DOPC and DDAO without any concentration dependent type of interaction within the studied range (0-30 wt $\%$ of DDAO). DDAO can play an important role in designing lipid-based systems for drug and DNA delivery (Hubčík et al. 2015; Liskayová et al. 2017). Differences in the geometric shape of the surfactant with alkyl chain shorter than phospholipid chains are causing creation of voids in the hydrophobic region of the bilayer, which is compensated by a trans-gauche isomerisation of alkyl and acyl chains. As a result, physical properties of the bilayer, e.g. fluidity (Balgavý et al. 1989) and thickness of the lipid bilayer (Dubničková et al. 1997; Uhríková et al. 2001; Karlovská et al. 2004b) are changed. More detailed small-angle neutron scattering (SANS) study of unilamellar liposomes (ULLs) of DOPC using the external $\mathrm{D}_{2} \mathrm{O} / \mathrm{H}_{2} \mathrm{O}$ contrast variation technique showed that increasing $\mathrm{n}_{\mathrm{DDAO}}: \mathrm{n}_{\mathrm{DOPC}}$ caused narrowing of the hydrocarbon region in DOPC bilayers (Belička et al. 2014b). Increasing concentration of DDAO in DOPC and DOPC-cholesterol (CHOL) model membranes leads to defect creation, as detected by leakage of fluorescent probe calcein (Huláková et al. 2013, 2015). DDAO destabilized the bilayer in ULLs and solubilized it into mixed phospholipidDDAO micelles above certain threshold DDAO concentration (Uhríková et al. 2001).

Several authors use the term solubilisation for the whole complex of phenomena that can be observed in model membrane-surfactant interaction in a wide range of surfactant concentration. According to characteristic types of lipid-surfactant aggregates, three stages are distinguished in the process of solubilisation (suggested by Helenius and Simons 1975). In the first stage, surfactant molecules distribute between the lipid bilayer and aqueous media. They start to influence physical properties of bilayer and induce formation of defects and pores (Ruiz et al. 1988; Memoli et al. 1999; Cócera et al. 2003) in the bilayer by stabilising the hydrophobic edges of a bilayer with a surfactant-rich rim (Heerklotz 2008). The next stage starts when surfactant reaches a concentration that causes bilayer disintegration. At this stage, mixed micelles are present, as well as remaining surfactant-saturated bilayers and surfactant monomers. In the last stage, high surfactant to lipid ratio forces all bilayer fragments with incorporated surfactant to transform into mixed micelles. The shape of micelles is usually cylinder with tendency to be transformed to oblate or spherical micelle with further surfactant concentration increase. This model is widely accepted and explained in other papers (Helenius and Simons 1975; Lichtenberg 1985; Goni and Alonso 2000; Ahyayauch et al. 2010; Heerklotz and Blume 2012; Lichtenberg et al. 2013a, 2013b; Chen et al. 2017). The ability of DDAO to form defects in the bilayer and subsequently disrupt the membrane structure completely is the cause of biocidal properties of DDAO.

Solubilisation induced by DDAO was studied before on unilamellar and multilamellar liposomes (MLLs) of egg yolk phosphatidylcholine (EYPC). Partition coefficient of DDAO between ULLs and non-buffered aqueous phase was determined turbidimetrically in Hrubšová et al. (2003). According to our unpublished results, $\mathrm{pH}$ changes from 6.4 to 7.0 when concentration of DDAO increases from $0.05 \mathrm{mmol} / \mathrm{dm}^{3}$ to $3 \mathrm{mmol} / \mathrm{dm}^{3}$ in a dispersion of ULLs of EYPC $\left(0.4 \mathrm{mmol} / \mathrm{dm}^{3}\right)$ prepared in water. Because $\mathrm{pK}$ value is $\sim 5$, a part of DDAO molecules is positively charged. In Karlovská et al. (2004a), solubilisation of MLLs of EYPC was studied in buffered aqueous phase $(\mathrm{pH}=8)$, but attainment of partitioning equilibrium of DDAO molecules in multilamellar system is not guaranteed. The aim of this paper is to broaden the above-described knowledge and to study the interaction of DDAO molecules in their neutral form with model membranes. Liposomes were therefore prepared in phosphate buffered saline (PBS buffer, $\mathrm{pH}$ 7.5).

We use model membranes created by DOPC and DOPC enriched by CHOL. Phosphatidylcholines (PC) account for $>50 \%$ of the phospholipid in most eukaryotic membranes. $\mathrm{CHOL}$ is present in eukaryotic plasma membranes in large amounts (20-40 mol\%) as well (Huang et al. 1999; Ohvo-Rekilä et al. 2002; Mouritsen and Zuckermann 2004). To mimic the physiological composition of mammalian membrane, we have used $33 \mathrm{~mol} \%$ of $\mathrm{CHOL}$ in our samples. The effect of CHOL on the solubilisation of ULLs made of EYPC by DDAO was studied in our previous paper (Huláková et al. 2015) but because only one EYPC concentration was used, the determination of partition coefficient of DDAO was not possible. 
In the present paper, the solubilising effect of DDAO on the liposomes is studied using static light scattering (turbidimetry), fluorescence probe leakage method and smallangle neutron scattering with emphasis on the observation of the changes in the size and type of aggregates present during the solubilisation process. Partition coefficient of DDAO is calculated.

\section{Materials and Methods}

\section{Materials}

DOPC purchased from Avanti Polar Lipids (USA), CHOL and DDAO obtained from Sigma-Aldrich (Germany) were $>99 \%$ pure and were used without further purification. Calcein (Bis[N,N-bis(carboxymethyl)aminomethyl]fluorescein) was purchased from Acros Organics (USA). Other used chemicals: $\mathrm{NaOH}, \mathrm{K}_{2} \mathrm{HPO}_{4}$ (CentralChem, Slovakia), $\mathrm{KH}_{2} \mathrm{PO}_{4}$ (Merck, Germany) and $\mathrm{NaCl}$ (Slavus, Slovakia) were of analytical grade. For column chromatography Sephadex G-50 (fine) (Pharmacia, Fine Chemicals AB, Sweden), Whatman GF/B glass microfiber filter (GE Healthcare, UK), $15 \mathrm{ml}$ disposable polypropylene centrifuge tubes and $5 \mathrm{ml}$ disposable syringes were used.

\section{Liposomes preparation and characterization}

DOPC and DOPC-CHOL ( $\left.\mathrm{n}_{\text {DOPC }}: \mathrm{n}_{\mathrm{CHOL}}=2: 1 \mathrm{~mol} / \mathrm{mol}\right)$ model membranes were prepared. Weighted amounts of dry lipids DOPC and DOPC-CHOL were in glass tubes. DOPC-CHOL mixtures were co-solubilised by dissolving in chloroform. Chloroform was evaporated under a stream of gaseous nitrogen to dryness, followed by evacuation in a vacuum chamber using rotary oil pump for $8 \mathrm{~h} .50 \mathrm{mmol} /$ $\mathrm{dm}^{3}$ PBS buffer with $\mathrm{pH} 7.5$, consisting of $7.6 \mathrm{mmol} / \mathrm{dm}^{3}$ $\mathrm{KH}_{2} \mathrm{PO}_{4}, 42.4 \mathrm{mmol} / \mathrm{dm}^{3} \mathrm{~K}_{2} \mathrm{HPO}_{4}$ and $150 \mathrm{mmol} / \mathrm{dm}^{3}$ $\mathrm{NaCl}$ was prepared using redistilled water.

For turbidity measurements, dry lipid film of DOPC or DOPC-CHOL was prepared as described above. Adequate amount of lipid film was hydrated with $5 \mathrm{ml}$ of PBS buffer to obtain lipid concentration $13 \mathrm{mmol} / \mathrm{dm}^{3} .24 \mathrm{~h}$ long hydration allowed spontaneous formation of MLLs and a vortex mixer was used from time to time to obtain homogenous dispersion. MLLs dispersion was extruded (LiposoFast-Basic Extruder) 51 times through $100 \mathrm{~nm}$ polycarbonate filter (Olson et al. 1979; MacDonald et al. 1991). Dispersion was then used to prepare a set of 25 samples with constant concentration of lipid $0.4 \mathrm{mmol} / \mathrm{dm}^{3}$. Samples with different concentrations of lipid (for DOPC 0.2; $0.3 ; 0.35 ; 0.4 \mathrm{mmol} / \mathrm{dm}^{3}$ and for DOPC-CHOL mixtures $0.2 ; 0.3 ; 0.4 \mathrm{mmol} / \mathrm{dm}^{3}$ ) were prepared. Similar procedure was followed for all of them. In total, 7 independent turbidity experiments have been performed.
One additional set of samples with DOPC concentration $0.4 \mathrm{mmol} / \mathrm{dm}^{3}$ was prepared using liposomes extruded at first 51 times through a $100 \mathrm{~nm}$ filter and consequently 51 times through a $50 \mathrm{~nm}$ filter.

For fluorescent probe leakage measurements, $10 \mathrm{mmol} / \mathrm{dm}^{3}$ calcein solution was prepared by dissolving adequate amount of crystalline calcein in minimum effective amount of $\mathrm{NaOH}$ solution $\left(1 \mathrm{~mol} / \mathrm{dm}^{3}\right)$, followed by heavy stirring using a vortex and diluting with PBS to required concentration ( $\mathrm{pH}$ 7.46). Adequate amount of dry lipid film was hydrated with $2 \mathrm{ml}$ of calcein solution and vortexed resulting in formation of MLLs, which were then extruded 51 times through $100 \mathrm{~nm}$ polycarbonate filter. The liposomes containing calcein were separated from the untrapped calcein in extraliposomal space by column chromatography using Sephadex G-50 fine gel swollen in PBS (Benachir and Lafleur 1995; Memoli et al. 1999; Huláková et al. 2015). For example, $40 \mathrm{mmol} / \mathrm{dm}^{3}$ dispersion of DOPC MLLs was prepared by spontaneous $24 \mathrm{~h}$ long lipid film hydration with occasional vortexing. The lipid dispersion was used (after the extrusion and gel chromatography) to prepare a set of samples with lipid concentration $0.4 \mathrm{mmol} / \mathrm{dm}^{3}$. Four sets of samples were prepared similarly for each type of a model membrane (DOPC, DOPC-CHOL) with studied concentrations of DOPC $\left(0.1 ; 0.2 ; 0.3 ; 0.4 \mathrm{mmol} / \mathrm{dm}^{3}\right)$, which means that 8 independent fluorescent probe leakage experiments have been performed.

For SANS measurements, $\mathrm{D}_{2} \mathrm{O}$-PBS buffer was prepared as described above, but $\mathrm{D}_{2} \mathrm{O}$ was used instead of $\mathrm{H}_{2} \mathrm{O}$. Lipid film of DOPC or DOPC-CHOL was hydrated with $\mathrm{D}_{2} \mathrm{O}$ PBS (for $24 \mathrm{~h}$ ) to yield lipid dispersion (lipid concentration $40 \mathrm{mmol} / \mathrm{dm}^{3}$ ). MLLs were extruded 51 times through 100 $\mathrm{nm}$ and subsequently 51 times through $50 \mathrm{~nm}$ polycarbonate filter. Extruded liposomes prepared in $\mathrm{D}_{2} \mathrm{O}$-PBS buffer were mixed with $\mathrm{D}_{2} \mathrm{O}$-PBS buffer and increasing volumes of DDAO solution in $\mathrm{D}_{2} \mathrm{O}-\mathrm{PBS}$ to reach the molar ratio $\mathrm{n}_{\text {DDAO }} \mathrm{n}_{\text {LIPID }}$ in the range of $0-5(\mathrm{~mol} / \mathrm{mol})$ and final sample volume $1 \mathrm{~cm}^{3}$. The final concentration of lipid (DOPC or DOPC-CHOL) in each sample was $8.9 \mathrm{mmol} / \mathrm{dm}^{3}$. The lipid+DDAO concentration expressed by weight percent increases from $0.64 \mathrm{wt} \%$ for DOPC without DDAO to 1.57 $\mathrm{wt} \%$ at $\mathrm{n}_{\text {DDAO }} \mathrm{n}_{\text {LIPID }}=5$ and similarly for DOPC-CHOL samples. Several special DOPC samples (1 wt\%) were prepared in absence of DDAO with different aqueous phase: a) $100 \% \mathrm{D}_{2} \mathrm{O}$; b) $150 \mathrm{mmol} / \mathrm{dm}^{3}$ of $\mathrm{NaCl}$ in $\mathrm{D}_{2} \mathrm{O}$; c) 150 $\mathrm{mmol} / \mathrm{dm}^{3}$ of $\mathrm{NaCl}$ in $50 \mathrm{mmol} / \mathrm{dm}^{3} \mathrm{D}_{2} \mathrm{O}$-PBS. Extrusion of 51 times through $50 \mathrm{~nm}$ filter was applied.

\section{Turbidity measurements}

Decrease in the particle size, typical feature of the solubilisation process, was researched turbidimetrically using Agilent 8453A UV-visible Spectrophotometer (Hewlet Packard, USA). The loss of intensity of transmitted light due to the scat- 
tering effect of particles suspended in samples was observed in the mode of absorbance measurement. We have used a term "turbidity" instead of absorbance. Turbidity $\left(\mathrm{A}_{\mathrm{T}}\right)$ was evaluated at $400 \mathrm{~nm}$, out of the absorption peak of used lipids. Liposomes with different lipid concentrations were prepared (see section Liposomes preparation and characterization) with increasing concentration of DDAO $\left(0-4.5 \mathrm{mmol} / \mathrm{dm}^{3}\right)$ added $3 \mathrm{~h}$ before measurement. Typical three-stage dependence of turbidity on the surfactant concentration is shown in the Figure 1. Surfactant concentrations causing the turning points in the course of the dependence (we will use term "critical concentrations") are usually calculated to characterise this type of dependence. The turning points are concentrations of DDAO at particular steps in the solubilisation process, $\mathrm{D}_{\mathrm{t}}^{\mathrm{SAT}}$ and $\mathrm{D}_{\mathrm{t}}^{\mathrm{SOL}} . \mathrm{D}_{\mathrm{t}}^{\mathrm{SAT}}$ represents the total concentration of DDAO in the sample, which after partitioning between liposomes and aqueous solution saturates the bilayer sufficiently to begin the transformation into mixed micelles (the transition between the first and the second stage). $\mathrm{D}_{t}^{\mathrm{SOL}}$ is the concentration of DDAO that causes complete solubilisation (transition of all present bilayers into mixed micelles). $\mathrm{D}_{\mathrm{t}}^{\mathrm{SOL}}$ characterises transition from the second to the final third stage of solubilisation. A bilinear function was used to determine the turning points between the individual stages:

$$
\begin{aligned}
y= & (k x+q) 0.5\left(1-\frac{x-D_{t}}{\left|x-D_{t}\right|}\right)+\left(m x+D_{t}(k-m)\right. \\
& +q) 0.5\left(1+\frac{x-D_{t}}{\left|x-D_{t}\right|}\right)
\end{aligned}
$$

where $\mathrm{y}=\mathrm{kx}+\mathrm{q}$ is the equation of the straight line before the turning point $\left(x \leq D_{t}\right)$ and $y=m x+r$ represents the straight line after the turning point $\left(x \geq D_{t}\right)$. Symbol $D_{t}$ is the $\mathrm{x}$-coordinate of the turning point (critical concentration). The data were fitted using one bilinear function to find $\mathrm{D}_{\mathrm{t}}^{\mathrm{SAT}}$ and another bilinear function to find $\mathrm{D}_{\mathrm{t}}^{\mathrm{SOL}}$ (for an example see Figure 1, full line). The equation of the straight line in the second stage is identical for both fits.

The solubilisation process is also described by a concentration of DDAO in the sample at which the turbidity value is half the value in the first phase (Hrubšová et al. 2003; Karlovská et al. 2004a). In this work, we will call it $\mathrm{D}_{\mathrm{t}}^{\mathrm{MID}}$ and determine its numerical value by fitting the dependence $A_{T}=f\left(c_{D D A O}\right)$ with reverse sigmoid function

$$
A_{T}=A_{T, \text { min }}+\frac{A_{T, \text { max }}-A_{T, \text { min }}}{1+\exp \left(-\frac{c_{D D A O}-D_{t}^{M I D}}{d c_{D D A O}}\right)}
$$

where $A_{T, m a x}$ is the maximum turbidity, $A_{T, m i n}$ is the minimum turbidity and $\mathrm{D}_{t}^{\mathrm{MID}}$ is the midpoint of the sigmoid, $\mathrm{dc}_{\mathrm{DDAO}}$ characterises the width of the transition from liposomes to mixed micelles.

\section{Fluorescence measurements}

Increasing concentration of DDAO in the model membrane in the first stage of solubilisation leads to defects creation followed by membrane permeabilisation (Memoli et al. 1999; Huláková et al. 2013, 2015). Pore formation can be observed using the fluorescent probe leakage technique. Fluorescence measurements were carried out using Flouromax 4 spectrofluorometer (Horiba Jobin Yvon, USA). Emission spectra (wavelength interval 490-580 nm) were measured using excitation wavelength of $485 \mathrm{~nm}$. The fluorescence intensity was evaluated at maximum of calcein emission within the range 513-520 $\mathrm{nm}$.

The dependence of fluorescence intensity on the concentration of calcein is in the first part linear, then it reaches maximum at about $20 \mu \mathrm{mol} / \mathrm{dm}^{3}$, beyond which the fluorescence signal starts to decrease and at approximately $100 \mu \mathrm{mol} / \mathrm{dm}^{3}$ is negligible owing to self-quenching. The samples were prepared so that encapsulated calcein fluorescence was insignificant. After surfactant addition, calcein leaked into extraliposomal space, where it was diluted (to the linear part of the dependence) and the fluorescence increase was monitored.

Calcein leakage experiments were performed on samples with four different lipid concentrations (see section Liposomes preparation and characterization) and increasing concentration of DDAO from 0 to $1.7 \mathrm{mmol} / \mathrm{dm}^{3}$ (depending on the concentration of lipid). Adequate amounts of $10 \mathrm{mmol} / \mathrm{dm}^{3} \mathrm{DDAO}$ stock solution were added to samples $3 \mathrm{~h}$ before measurement.

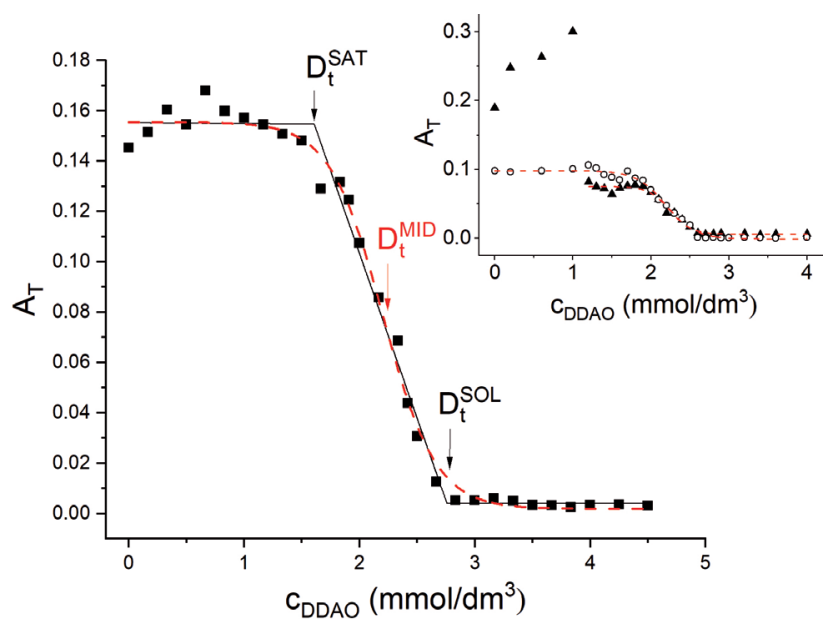

Figure 1. Dependence of turbidity $\left(\mathrm{A}_{\mathrm{T}}\right)$ on the concentration of added DDAO until complete solubilisation of all bilayers $\left(\mathrm{c}_{\mathrm{DOPC}+\mathrm{CHOL}}=\right.$ $0.45 \mathrm{mmol} / \mathrm{dm}^{3}$ ). Arrows indicate the positions of evaluated critical concentrations of DDAO $D_{t}{ }^{S A T}, D_{t}{ }^{S O L}$ using bilinear functions (full line) and $D_{t}{ }^{M I D}$ using reverse sigmoid (dashed line) function. The inset shows the comparison of the solubilisation of DOPC liposomes $\left(c_{\text {DOPC }}=0.4 \mathrm{mmol} / \mathrm{dm}^{3}\right)$ extruded through $100 \mathrm{~nm}$ filter (circles) and $100 \mathrm{~nm}$ and consequently $50 \mathrm{~nm}$ filter (triangles). 
Typical three-stage course of the dependence of fluorescence intensity on the DDAO concentration can be seen in the Figure 2. Transient pores created at low surfactant concentration can cause gentle rise in fluorescence intensity in the first part of dependence $\left(\mathrm{c}_{\mathrm{DDAO}}<\mathrm{D}_{\mathrm{t}}{ }^{\mathrm{PERT}}\right)$. Stabilisation of the pores upon increase of DDAO concentration leads to the next stage of the dependence $\left(\mathrm{D}_{\mathrm{t}}{ }^{\mathrm{PERT}}<\mathrm{c}_{\mathrm{DDAO}}<\mathrm{D}_{\mathrm{t}}^{\mathrm{RLS}}\right)$. $\mathrm{D}_{\mathrm{t}}^{\mathrm{PERT}}$ signifies the DDAO concentration causing the onset of a massive release of the probe encapsulated inside the liposomes. The DDAO concentration at which the fluorescence intensity reached a stable value that is not influenced by a subsequent addition of DDAO is marked as $\mathrm{D}_{\mathrm{t}}{ }^{\mathrm{RLS}}$. These two critical DDAO concentrations were evaluated by fitting with bilinear function (Equation (1)), similarly as described for turbidity measurements.

\section{Partition coefficient calculations}

Molar partition coefficient $\left(\mathrm{K}_{\mathrm{p}}\right)$ of amphiphilic molecule between lipid and aqueous phase, in equilibrium state, is defined as the ratio of molar concentration of amphiphile in lipid phase - in our case in lipid bilayers $\left(D_{b}\right.$, subscript b represents bilayer) to its molar concentration in aqueous phase $\left(D_{w}\right.$, subscript w stands for water or water-based buffer)

$\mathrm{K}_{\mathrm{p}}=\frac{\mathrm{D}_{\mathrm{b}}}{\mathrm{D}_{\mathrm{w}}}$

In the present paper, we are calculating partition coefficient of the surfactant DDAO between the lipid bilayers (DOPC or DOPC-CHOL) and the water phase following the procedure previously described in Hrubšová et al. (2003). Briefly, after substituting the concentration as the amount (n) of DDAO in a specific phase (specified by a subscript b or w) divided by the volume $(V)$ of that phase: $D_{b}=n_{b} / V_{b} ; D_{w}=$ $\mathrm{n}_{\mathrm{W}} / \mathrm{V}_{\mathrm{W}}$, the Equation (3) can be rewritten as

$\mathrm{K}_{\mathrm{p}}=\frac{\mathrm{n}_{\mathrm{b}} \cdot \mathrm{V}_{\mathrm{w}}}{\mathrm{n}_{\mathrm{w}} \cdot \mathrm{V}_{\mathrm{b}}}$

The total amount of DDAO in the sample $\left(n_{t}\right)$ is a sum of the amount of membrane-bound DDAO $\left(n_{b}\right)$ and the amount of DDAO monomers in the aqueous phase $\left(\mathrm{n}_{\mathrm{w}}\right)$. Concentration of DDAO in the bilayer can be expressed as

$\frac{\mathrm{n}_{\mathrm{b}}}{\mathrm{V}_{\mathrm{b}}}=\frac{\mathrm{n}_{\mathrm{t}}}{\mathrm{V}_{\mathrm{t}}} \cdot \frac{\mathrm{K}_{\mathrm{p}}}{1+\mathrm{K}_{\mathrm{p}} \cdot \frac{\mathrm{V}_{\mathrm{b}}}{\mathrm{V}_{\mathrm{t}}}}$

where the approximation $\mathrm{V}_{\mathrm{b}}$ « $\mathrm{V}_{\mathrm{W}}$ is used. Then the total volume of the sample $V_{t}$ is approximately equal to $V_{w}$. The volume of a bilayer $\left(\mathrm{V}_{\mathrm{b}}\right)$ can be expressed using total amount of lipid $\left(n_{L}\right)$, molar mass of a lipid $\left(M_{L}\right)$ and density of a bilayer $\left(\rho_{b}\right)$

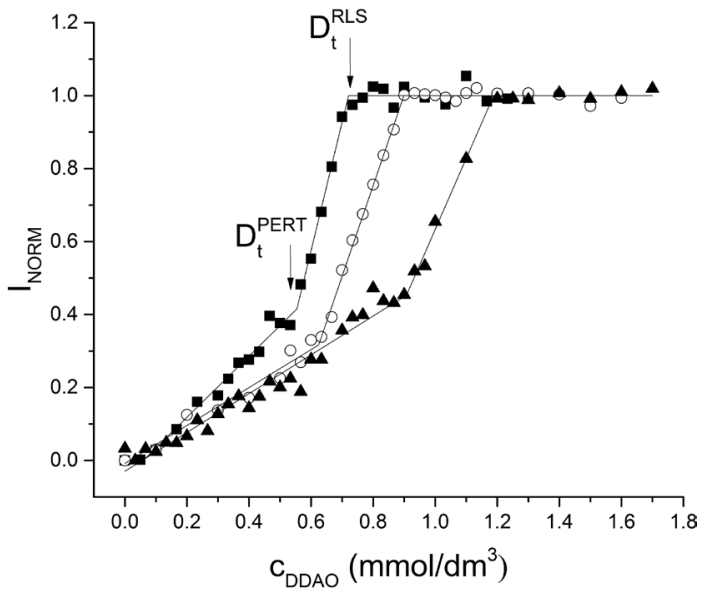

Figure 2. Dependence of the normalised fluorescence intensity ( $\mathrm{I}_{\mathrm{NORM}}$ ) of fluorescent probe calcein on the concentration of DDAO added to the DOPC-CHOL dispersion. Comparison of three different concentrations of lipid: $\mathrm{c}_{\mathrm{DOPC}+\mathrm{CHOL}}=0.3 \mathrm{mmol} / \mathrm{dm}^{3}$ (squares); $0.45 \mathrm{mmol} / \mathrm{dm}^{3}$ (circles); $0.6 \mathrm{mmol} / \mathrm{dm}^{3}$ (triangles). The arrows indicate the position of critical DDAO concentrations $\mathrm{D}_{t}{ }^{\text {PERT }}$ and $\mathrm{D}_{t}{ }^{\mathrm{RLS}}$ at the lowest lipid concentration. The intensity was normalised for better graphical comparison of the overall trend of the curves.

$\mathrm{V}_{\mathrm{b}}=\frac{\mathrm{m}_{\mathrm{L}}}{\rho_{\mathrm{b}}}=\frac{\mathrm{n}_{\mathrm{L}} \cdot \mathrm{M}_{\mathrm{L}}}{\rho_{\mathrm{b}}}$

In case of a mixed bilayer, e.g. DOPC-CHOL, molar mass $\mathrm{M}_{\mathrm{L}}$ can be calculated using mole fractions of DOPC $\left(\mathrm{X}_{\mathrm{DOPC}}\right)$ and $\mathrm{CHOL}\left(\mathrm{X}_{\mathrm{CHOL}}\right)$

$\mathrm{M}_{\mathrm{DOPC}+\mathrm{CHOL}}=\mathrm{X}_{\mathrm{DOPC}} \cdot \mathrm{M}_{\mathrm{DOPC}}+\mathrm{X}_{\mathrm{CHOL}} \cdot \mathrm{M}_{\mathrm{CHOL}}$

At $25^{\circ} \mathrm{C}$ the density of DOPC bilayer is $\rho_{\mathrm{DOPC}}=1.0062$ $\mathrm{g} / \mathrm{cm}^{3}$ and the density of DOPC-CHOL $(2: 1 \mathrm{~mol} / \mathrm{mol})$ mixed bilayer is $\rho_{\mathrm{DOPC}+\mathrm{CHOL}}=1.0076 \mathrm{~g} / \mathrm{cm}^{3}$ (calculated from densitometric data of Gallová et al. 2015).

Total concentration of DDAO $\left(D_{t}\right)$ in the sample is

$\mathrm{D}_{\mathrm{t}}=\frac{\mathrm{n}_{\mathrm{t}}}{\mathrm{V}_{\mathrm{t}}}$

After inserting the substituting Equations (6) and (8) into the Equation (5) we will get

$\frac{n_{b}}{n_{L}} \cdot \frac{\rho_{b}}{M_{L}}=D_{t} \cdot \frac{K_{p}}{1+K_{p} \cdot \frac{n_{L} \cdot M_{L}}{V_{t} \cdot \rho_{b}}}$

The Equation (9) can be then modified so that it describes linear dependence of $\mathrm{D}_{t}$ on the concentration of lipid $\left(\mathrm{c}_{\mathrm{L}}\right)$. To do that, substitutions $\mathrm{n}_{\mathrm{b}} / \mathrm{n}_{\mathrm{L}}=\mathrm{R}_{\mathrm{e}}$ (effective molar ratio) and $\mathrm{n}_{\mathrm{L}} / \mathrm{V}_{\mathrm{t}}=\mathrm{c}_{\mathrm{L}}$ need to be executed. 
$D_{t}=R_{e} \cdot \frac{\rho_{b}}{M_{L}} \cdot \frac{1}{K_{p}}+R_{e} \cdot c_{L}$

The slope in the linear dependence of $D_{t}=f\left(c_{L}\right)$ (Figure 3) is the effective molar ratio $\left(\mathrm{R}_{\mathrm{e}}\right)$ of the amount of DDAO integrated into the bilayer $\left(n_{b}\right)$ to the amount of lipid $\left(n_{L}\right)$. We used experimentally determined critical concentrations for $D_{t}$ in Equation (10) to calculate $R_{e}$ in the particular steps of solubilisation process. For example, $\mathrm{R}_{\mathrm{e}}{ }^{\mathrm{SAT}}$ corresponds to the effective molar ratio causing the onset of solubilisation (complete saturation of present bilayers by surfactant). $R_{e}$ values are constant for a specific surfactant-lipid mixture and are independent of lipid concentration. They refer to the effective amount of surfactant in the surfactant-lipid mixed assemblies under equilibrium conditions.

All five experimentally acquired linear dependencies (from turbidity and fluorescent spectroscopy data) of critical DDAO concentrations $\left(D_{t}\right)$ on the concentration of lipid $\left(c_{\mathrm{DOPC}}\right.$ or $\left.\mathrm{c}_{\mathrm{DOPC}+\mathrm{CHOL}}\right)$ were fitted at the same time with a model of global fit (Equation (10), see Fig. 3) using MultiData Fit Mode in Origin software (Version 2018b. OriginLab Corporation, Northampton, MA, USA).

With the constant ratio $\rho_{\mathrm{b}} / \mathrm{M}_{\mathrm{L}}$ as a fixed parameter $\left(1283 \mathrm{mmol} / \mathrm{dm}^{3}\right.$ for DOPC and $1543 \mathrm{mmol} / \mathrm{dm}^{3}$ for DOPC$\mathrm{CHOL})$, the global model was able to fit individual linear dependencies with their particular slopes $\left(\mathrm{R}_{\mathrm{e}}\right)$ and calculate a shared partition coefficient $K_{p}$ for all five dependencies. The term "shared partition coefficient" is used to indicate that in the model of global fit, partition coefficient was denoted as a shared parameter for all the input data.

\section{Small angle neutron scattering}

SANS measurements were performed at the small-angle time-of-flight spectrometer YuMO at the IBR-2 fast pulsed reactor of FLNP JINR Dubna (Russia) (Kuklin et al. 2017; Soloviev et al. 2017) at $25.0 \pm 0.1^{\circ} \mathrm{C}$. The samples were kept in quartz cells (Hellma, Müllheim, Germany) with a path length of $2 \mathrm{~mm}$ and measured $24 \mathrm{~h}$ after extrusion. The scattered intensity was normalised using vanadium standard and corrected for the background effect by the blank.

Experimental data were analysed using SasView fitting software version 4.1 (Doucet et al. 2017). The ideal model scattering curves were smeared by the instrument resolution $\sim 10 \%$. The average excess of scattering length density per unit mass $(\Delta \rho)$ was calculated from known $\mathrm{n}_{\text {DDAO }} \mathrm{n}_{\text {LIPID }}$ in the sample using the partition coefficient (Table 1) and appropriate molecular volumes and molecular weights (Belička et al. 2014a; Gallová et al. 2015).

Scattering curves (dependencies of intensity of scattered neutrons $I(q)$ on the scattering vector $(q)$ measured for $\mathrm{n}_{\mathrm{DDAO}}: \mathrm{n}_{\text {LIPID }}$ in the range $0-1 \mathrm{~mol} / \mathrm{mol}$ were analysed using a paracrystal lamellar model (Bergström et al. 1999) with respect to the lamella thickness $\left(\mathrm{d}_{\mathrm{L}}\right)$ distribution and the number of lamellae in a single cluster. The stacks of lamellae (infinite in lateral dimension) separated by water layers are treated as a paracrystal to account for the repeating spacing $\mathrm{d}$ (sum of one lamella thickness and one water layer thickness). The repeat spacing is further characterized by a Gaussian polydispersity. In our case, lamella is represented by a lipid bilayer. In this model, scattering intensity $\mathrm{I}(\mathrm{q})$ is given by

$\mathrm{I}(\mathrm{q})=2 \pi(\Delta \rho)^{2} \Gamma_{\mathrm{m}} \frac{\mathrm{P}_{\mathrm{bil}}(\mathrm{q})}{\mathrm{q}^{2}} \mathrm{Z}_{\mathrm{N}}(\mathrm{q})$

where $\Delta \rho$ is the difference in scattering length per unit mass of solute between particles and solvent and $\Gamma_{\mathrm{m}}$ is the mass per area of the bilayer. The form factor is here separated into one contribution that accounts for the cross section of a planar bilayer

$\mathrm{P}_{\mathrm{bil}}(\mathrm{q})=\left(\frac{\sin (\mathrm{q} \xi)}{\mathrm{q} \xi}\right)^{2}$
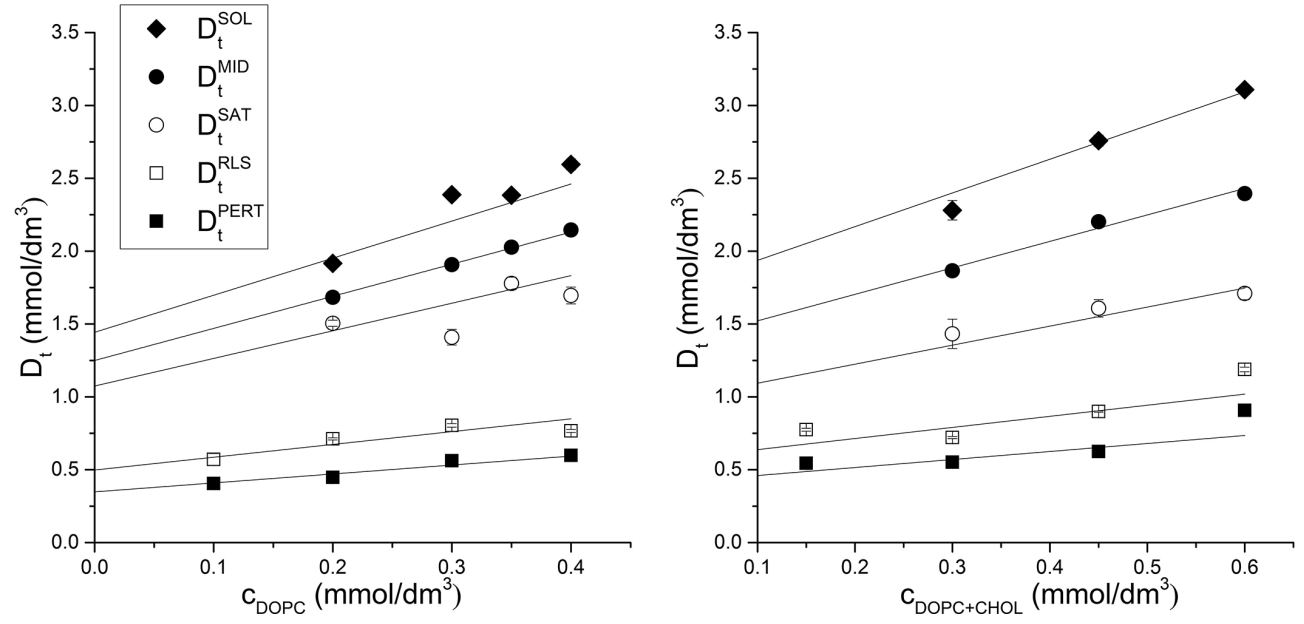

Figure 3. Linear dependencies of critical DDAO concentrations on the concentration of DOPC (on the left) and DOPC-CHOL (on the right). 
where $\xi$ is half the bilayer thickness, $\xi=\mathrm{d}_{\mathrm{L}} / 2$, and a factor proportional to $\mathrm{q}^{-2}$ which is typical for an infinitively large two-dimensional sheet. $\mathrm{Z}_{\mathrm{N}}(\mathrm{q})$ describes the interference effects for aggregates formed by more than one layer. It can be written as a function of the average number of layers $\left(\mathrm{N}_{\mathrm{L}}\right)$

$\mathrm{N}_{\mathrm{L}}=\mathrm{x}_{\mathrm{N}} \mathrm{N}+\left(1-\mathrm{x}_{\mathrm{N}}\right)(\mathrm{N}+1)$

of two clusters consisting of $\mathrm{N}$ integer number of layers, the fraction of which is $\mathrm{x}_{\mathrm{N}}$ and $(\mathrm{N}+1)$, the fraction of which is $\left(1-\mathrm{x}_{\mathrm{N}}\right)$, respectively.

The SANS data for samples with $\mathrm{n}_{\text {DDAO }} \mathrm{n}_{\text {LIPID }}$ in the range $3-5 \mathrm{~mol} / \mathrm{mol}$ were analysed using a model of elliptical cylinder (Feigin and Svergun 1987; Pedersen 1997). L is the length of the cylinder and $\mathrm{V}_{\text {cyl }}$ is its volume. The cross section of the cylinder is elliptical. $\mathrm{R}_{\mathrm{MIN}}$ is ellipse minor radius and $v$ is the ratio of ellipse major to minor radius, it means $\mathrm{R}_{\text {MAJOR }}=v \mathrm{R}_{\text {MIN }}$. The scattering intensity is described by

$I(q)=\frac{(\Delta \rho)^{2}}{V_{c y l}} \int d \psi \int P_{c y l}(q, \alpha, \psi) \sin \alpha d \alpha$

The angle $\psi$ is defined as the orientation of the major axis of the ellipse with respect to the vector q. $\alpha$ is the angle between the axis of the cylinder and vector $\mathrm{q}$. The form factor $\mathrm{P}_{\text {cyl }}(\mathrm{q}, \alpha, \psi)$ can be expressed as

$\mathrm{P}_{\text {cyl }}(\mathrm{q}, \alpha, \psi)=\left[\frac{2 \mathrm{~J}_{1}(\mathrm{a}) \sin \mathrm{b}}{\mathrm{ab}}\right]^{2}$

where $\mathrm{J}_{1}(\mathrm{a})$ is the first order Bessel function; $\mathrm{a}, \mathrm{b}$ are given by $\mathrm{a}=\mathrm{qr}$ 'sin $\alpha, \mathrm{b}=\mathrm{L} / 2 \cos \alpha$ and

$\mathrm{r}^{\prime}=\frac{\mathrm{R}_{\mathrm{MIN}}}{\sqrt{2}}\left[\left(1+v^{2}\right)+\left(1-v^{2}\right) \cos \psi\right]^{1 / 2}$

For more detailed information about used fitting functions, see the SasView web page (http://www.sasview.org/ sasview/user/models/model_functions.html) and sources cited there.

Full lines in Figure 4 represent the best fits of experimental data applying the paracrystal lamellar model and a model of elliptical cylinder.

\section{Results}

Permeabilisation and solubilisation of prepared liposomes composed of DOPC and DOPC-CHOL at various concentrations induced by non-ionic (at $\mathrm{pH} \sim 7.5$ ) surfactant DDAO were researched. Solubilisation process, accompanied by a decrease of particle size, was monitored by turbidimetry. Pore formation was investigated at sub-lytic surfactant concentrations using fluorescent probe leakage method. Changes in the shape of lipid aggregates were studied by SANS.

\section{Turbidimetry and fluorescence spectroscopy}

Solubilisation process, monitored by changes in turbidity, of both DOPC and DOPC-CHOL model membranes was measured at various lipid concentrations. An example can be seen in the Figure 1. All measured dependencies followed the typical three-stage model described in the Introduction. For all dependencies, the critical concentrations have been calculated using the bilinear and reverse sigmoid fitting functions (Equations (1) and (2)). Identical course of the dependence of turbidity on DDAO concentration and the same $\mathrm{D}_{\mathrm{t}}^{\mathrm{SAT}}, \mathrm{D}_{\mathrm{t}}^{\mathrm{SOL}}$ and $\mathrm{D}_{\mathrm{t}}^{\mathrm{MID}}$ values were collected $3 \mathrm{~h}$ and $24 \mathrm{~h}$ after DDAO addition, equilibrium state of samples can be supposed after $3 \mathrm{~h}$. Critical concentrations determined turbidimetrically increase linearly with increasing concentration of lipid, both DOPC and DOPC-CHOL (Fig. 3).

Liposomes used for our turbidity and calcein leakage experiments were prepared by extrusion through filter with $100 \mathrm{~nm}$ pores. One turbidity experiment was repeated with

Table 1. Effective ratio $\left(\mathrm{R}_{\mathrm{e}}\right)$ of the amount of DDAO integrated into the DOPC or DOPC-CHOL bilayer $\left(\mathrm{n}_{\mathrm{b}}\right)$ to the amount of DOPC $\left(\mathrm{n}_{\mathrm{DOPC}}\right)$ or DOPC-CHOL $\left(\mathrm{n}_{\mathrm{DOPC}+\mathrm{CHOL}}\right)$

\begin{tabular}{|c|c|c|c|c|}
\hline \multirow{2}{*}{$\begin{array}{l}\text { Critical DDAO } \\
\text { concentration }\end{array}$} & \multicolumn{2}{|c|}{ DOPC } & \multicolumn{2}{|c|}{ DOPC-CHOL } \\
\hline & $\mathrm{R}_{\mathrm{e}}$ & $\mathrm{D}_{\mathrm{w}}\left(\mathrm{mmol} / \mathrm{dm}^{3}\right)$ & $\mathrm{R}_{\mathrm{e}}$ & $\mathrm{D}_{\mathrm{W}}\left(\mathrm{mmol} / \mathrm{dm}^{3}\right)$ \\
\hline $\mathrm{D}_{\mathrm{t}}^{\text {PERT }}$ & $0.61 \pm 0.08$ & $0.35 \pm 0.11$ & $0.55 \pm 0.11$ & $0.41 \pm 0.21$ \\
\hline $\mathrm{D}_{\mathrm{t}}^{\mathrm{RLS}}$ & $0.88 \pm 0.10$ & $0.50 \pm 0.14$ & $0.76 \pm 0.14$ & $0.56 \pm 0.29$ \\
\hline $\mathrm{D}_{\mathrm{t}}^{\mathrm{SAT}}$ & $1.89 \pm 0.23$ & $1.07 \pm 0.32$ & $1.31 \pm 0.27$ & $0.96 \pm 0.51$ \\
\hline $\mathrm{D}_{\mathrm{t}}^{\mathrm{MID}}$ & $2.20 \pm 0.25$ & $1.25 \pm 0.36$ & $1.82 \pm 0.31$ & $1.34 \pm 0.67$ \\
\hline $\mathrm{D}_{\mathrm{t}}^{\mathrm{SOL}}$ & $2.54 \pm 0.30$ & $1.44 \pm 0.42$ & $2.31 \pm 0.40$ & $1.71 \pm 0.85$ \\
\hline $\mathrm{K}_{\mathrm{p}}$ & \multicolumn{2}{|c|}{$2262 \pm 379$} & \multicolumn{2}{|c|}{$2092 \pm 594$} \\
\hline
\end{tabular}

$\mathrm{D}_{\mathrm{w}}$, concentration of monomeric surfactant in the water phase; $\mathrm{K}_{\mathrm{p}}$, molar partition coefficient of DDAO between DOPC or DOPC-CHOL bilayer and aqueous phase. For more information, see Materials and Methods. 


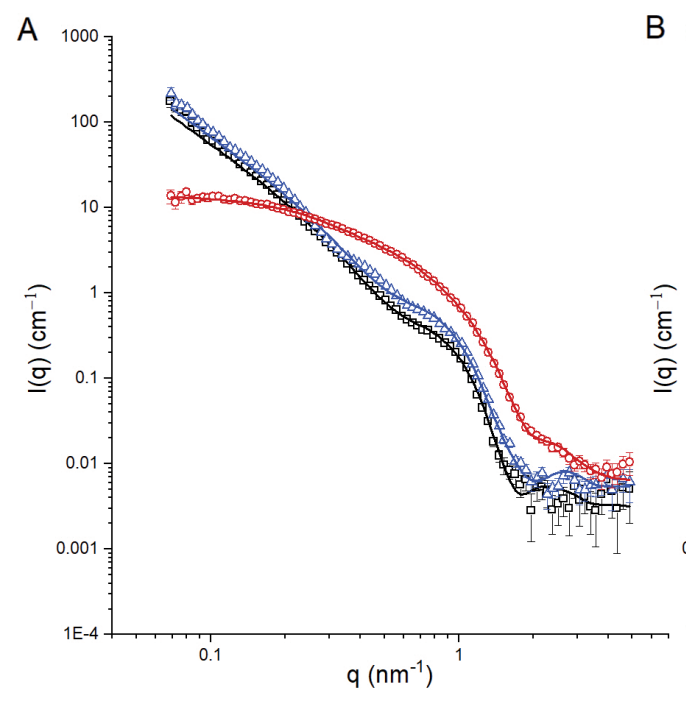

Figure 4. Scattering intensity as a function of scattering vector $\mathrm{q}$ for samples containing aggregates of DOPC (A) and DOPC-CHOL (B) mixed with various amounts of DDAO. This figure shows data and their fits for neat DOPC/DOPCCHOL samples (squares) and DDAO containing samples $\mathrm{n}_{\text {DDAO }}: \mathrm{n}_{\text {LIPID }}=1$ (triangles) and 5 (circles). Solid lines represent the results from fits with a lamellar paracrystal model $\left(\mathrm{n}_{\text {DDAO }}: \mathrm{n}_{\text {LIPID }}=0\right.$ and 1$)$ and with a model of elliptical cylinder ( $\left.\mathrm{n}_{\text {DDAO: }} \mathrm{n}_{\text {LIPID }}=5\right)$.
DOPC liposomes extruded through $100 \mathrm{~nm}$ and consequently through $50 \mathrm{~nm}$ filter, because liposomes prepared this way were used in the SANS experiment. As can be seen in the inset in the Figure 1, higher values of turbidity were measured for these DOPC liposomes and turbidity further increased at the onset of the first stage of solubilisation. Turbidity suddenly decreased at DDAO concentration smaller than $\mathrm{D}_{\mathrm{t}}^{\mathrm{SAT}}$ and the solubilisation process was going on with critical concentrations very near to those for liposomes extruded only through $100 \mathrm{~nm}$ filter. Our results obtained using turbidimetry, calcein leakage and SANS can be therefore compared.

Pore formation was observed by fluorescent probe leakage method. Two critical concentrations $\left(D_{t}{ }^{\text {PERT }}\right.$ and $\left.D_{t}{ }^{R L S}\right)$ can be seen on the dependence of fluorescence intensity on the concentration of DDAO (Fig. 2). Two bilinear functions (Equation (1)) were used to calculate the critical concentrations, as described earlier. $\mathrm{D}_{\mathrm{t}}{ }^{\mathrm{PERT}}$ and $\mathrm{D}_{\mathrm{t}}{ }^{\mathrm{RLS}}$ increase linearly with increasing lipid concentration. As can be seen in the Figure 3, the fluorescence intensity reached a stable value $\left(D_{t}{ }^{R L S}\right)$ at lower DDAO concentration than is the calculated saturation point $\left(\mathrm{D}_{\mathrm{t}}^{\mathrm{SAT}}\right)$, known from the turbidity data.

\section{Partition coefficients calculations}

Linear dependence of critical DDAO concentrations (both from the turbidimetry and fluorescence spectroscopy data) on lipid concentration (Fig. 3) was used to determine the molar partition coefficient $\left(K_{p}\right)$ of DDAO (Hrubšová et al. 2003), the effective ratio $\mathrm{R}_{\mathrm{e}}$ (amount of DDAO in the lipid phase to the amount of lipid) and the molar concentration of DDAO in aqueous phase $\left(\mathrm{D}_{\mathrm{w}}\right)$ (Lichtenberg 1985; Partearroyo et al. 1992; de la Maza and Parra 1994; de la Maza et al. 1998; Cócera et al. 2003; Toro et al. 2009; Lichtenberg et al. 2013a, 2013b; Chen et al. 2017). $R_{e}$ and $K_{p}$ values were calculated using a global fitting function (Equation (10)) as described in section Partition coefficient calculations (in Materials and Methods). $\mathrm{D}_{\mathrm{w}}$ values were obtained by back-extrapolation of existing global function to zero DDAO concentration. All calculated $\mathrm{D}_{\mathrm{w}}$ values are lower than the DDAO critical micellar concentration $\left(2.1 \mathrm{mmol} / \mathrm{dm}^{3} ; 27^{\circ} \mathrm{C}\right.$ ) (Herrmann 1962). Therefore, we suggest that the solubilisation process took place by transbilayer mechanism (Kragh-Hansen et al. 1998). Calculated $R_{e}, D_{w}$ and $K_{p}$ values are shown in Table 1. Partition coefficient of DDAO in case of a bilayer consisting of pure DOPC is $\mathrm{K}_{\mathrm{p}}=2262 \pm 379$. For the membrane enriched in CHOL, the partition coefficient is $\mathrm{K}_{\mathrm{p}}=2092 \pm 594$. Within the experimental error, the partition coefficient does not considerably change when a third of DOPC molecules is substituted by CHOL.

\section{Small-angle neutron scattering}

The structure of aggregates of DOPC-DDAO and DOPCCHOL-DDAO prepared in $\mathrm{D}_{2} \mathrm{O}-\mathrm{PBS}$ buffer was studied by the SANS method. Despite the fact that the dispersion of DOPC was carefully extruded through a filter with $100 \mathrm{~nm}$ pores and consequently through a filter with $50 \mathrm{~nm}$ pores and the concentration of lipid was low $(\sim 0.6 \mathrm{wt} \%)$, scattering curves obtained with DOPC in $\mathrm{D}_{2} \mathrm{O}$-PBS showed a noticeable correlation peak at $\mathrm{q} \sim 1 \mathrm{~nm}^{-1}$ (Fig. 4A). This peak is present also after the addition of DDAO up to $\mathrm{n}_{\mathrm{DDAO}}: \mathrm{n}_{\mathrm{LIPID}}$ $=1$. Similarly, the correlation peak is observed for samples containing DOPC-CHOL bilayers, when prepared by the same working procedure (Fig. 4B). Correlation peak indicates aggregation of ULLs or presence of oligolamellar structures.

Due to the presence of the correlation peak, a model of unilamellar liposomes was not suitable to evaluate corre- 
sponding dependencies. Lamellar paracrystal model was used to analyse the SANS data for samples with $\mathrm{n}_{\text {DDAO }}: \mathrm{n}_{\text {LIPID }}$ in the range $0-1 \mathrm{~mol} / \mathrm{mol}$ (Figure 4 ). The model calculates the scattering from a stack of repeating lipid bilayers, which are infinite in lateral spacing and separated by water layers. The fitting procedure allows to determine the thickness of the lipid bilayer $d_{L}$, repeat spacing $d$ and a coefficient $N_{L}$ characterizing the number of bilayers interacting in the cluster. Small discrepancy between experimental data and fits in the region of low $q$ is caused by finite value of liposome diameter in comparison with the suggested infinite lateral dimension of the lamellae.

We found the lipid bilayer thickness $\mathrm{d}_{\mathrm{L}}=3.61 \pm 0.02 \mathrm{~nm}$ for neat DOPC bilayer (Fig. 5). The addition of CHOL to DOPC bilayer is accompanied by the increase of acyl chain ordering and thickening of the bilayer to $d_{L}=3.94 \pm 0.02 \mathrm{~nm}$. Similar relative increase in bilayer thickness after CHOL addition was observed previously in Kučerka et al. (2007) and Gallová et al. (2010). Absolute values of bilayer thicknesses in the above-cited references are higher than in the present work because a more complex model of bilayer with water penetration taken into account was used there. CHOLinduced increase in membrane thickness was observed in X-ray diffraction study of Gandhavadi et al. (2002) as well.

The intercalation of surfactant molecules into the lipid bilayer caused narrowing of the lipid bilayer. The thickness of DOPC bilayer decreased by about $0.3 \mathrm{~nm}$, while for DOPC-CHOL bilayer it is nearly $0.4 \mathrm{~nm}$ at the molar ratio $\mathrm{n}_{\text {DDAO }} \mathrm{n}_{\text {LIPID }}=1$ (Fig. 5). DDAO molecules create voids in the bilayer because of the mismatch in the chain length, which disturbs the chain packing and enables trans-gauche isomerisation of the hydrocarbon chains, thus resulting in thinner membrane. Elimination of free volume can be achieved by interdigitation or bending of the hydrocarbon chains as well (Balgavý and Devínsky 1996).

We found repeat spacing $\mathrm{d}$, the sum of thickness of the lipid bilayer and the aqueous layer, equal to $6.26 \pm 0.03 \mathrm{~nm}$ for DOPC. An increase in d to $6.64 \pm 0.03 \mathrm{~nm}$ for DOPC-CHOL is caused mainly by the thicker bilayer in the presence of CHOL. Undistinguished changes in repeat distance after addition of DDAO up to $\mathrm{n}_{\mathrm{DDAO}}: \mathrm{n}_{\mathrm{LIPID}}=0.5$ are followed by an increase to the value $\sim 6.75 \mathrm{~nm}$ for equimolar mixture of lipid and surfactant for both model systems. The polydispersity of repeat spacing was low (around $0.2 \%$ for $\mathrm{n}_{\mathrm{DDAO}}: \mathrm{n}_{\mathrm{DOPC}}=$ $0-0.5)$, it increased with further addition of DDAO and reached the value about $1 \%$ for $\mathrm{n}_{\mathrm{DDAO}}: \mathrm{n}_{\mathrm{DOPC}}=1$. Results regarding the bilayer thickness and repeat spacing of DOPC coincide well with literature (Nagle and Tristram-Nagle 2000; Kučerka et al. 2005; Pullmannová et al. 2012), as well as the influence of DDAO on the DOPC bilayer thickness (Belička et al. 2014b). We believe that this proves the suitability of the lamellar paracrystal model for our DOPC-DDAO and DOPC-CHOL-DDAO systems.
The correlation peak at $\mathrm{q} \sim 1 \mathrm{~nm}^{-1}$ (Fig. 4) points to aggregated ULLs or presence of oligolamellar structures. $\mathrm{N}_{\mathrm{L}}$, characterizing the number of interacting bilayers, was found to be close to 1.4 for all lamellar paracrystal model fits. According to Equation (13), our samples consist of $60 \%$ of non-interacting bilayers and $40 \%$ of oligolamellar objects with 2 bilayers on average. The microscopic shot (Fig. 6) shows aggregates of lipid structures larger than $10 \mathrm{~mm}$. Approximately $25 \mu \mathrm{l}$ of DOPC dispersion in $50 \mathrm{mmol} / \mathrm{dm}^{3}$ PBS and $150 \mathrm{mmol} / \mathrm{dm}^{3} \mathrm{NaCl}$, extruded 51 times through $100 \mathrm{~nm}$ polycarbonate filter, was placed into a vapour-tight sealing chamber and cover glass. Dispersion was then observed using the differential interference contrast (DIC) microscopy technique.

We have studied the influence of aqueous phase on the structure of DOPC aggregates prepared as described in section Liposomes preparation and characterization (in Materials and Methods; results not shown). Measurements were performed $3 \mathrm{~h}$ and $24 \mathrm{~h}$ after extrusion. As expected, DOPC in $\mathrm{D}_{2} \mathrm{O}$ measured after $3 \mathrm{~h}$ yielded scattering curves typical for non-interacting ULLs, in accordance with other authors (Uhríková et al. 2001; Kučerka et al. 2007; Belička et al. 2014b). Correlation peak at $\mathrm{q} \sim 1 \mathrm{~nm}^{-1}$ was observed in the scattering curves obtained using DOPC when 150 $\mathrm{mmol} / \mathrm{dm}^{3} \mathrm{NaCl}$ or $50 \mathrm{mmol} / \mathrm{dm}^{3} \mathrm{D}_{2} \mathrm{O}$-PBS with 150 $\mathrm{mmol} / \mathrm{dm}^{3} \mathrm{NaCl}$ are used as water phase. This suggests that the increase of ionic strength of the aqueous environment induces interaction among ULLs of DOPC resulting in their aggregation. Scattering curves obtained with samples containing $\mathrm{NaCl}$ or PBS did not change significantly in the time range from $3 \mathrm{~h}$ to $24 \mathrm{~h}$ after the extrusion, but the scat-

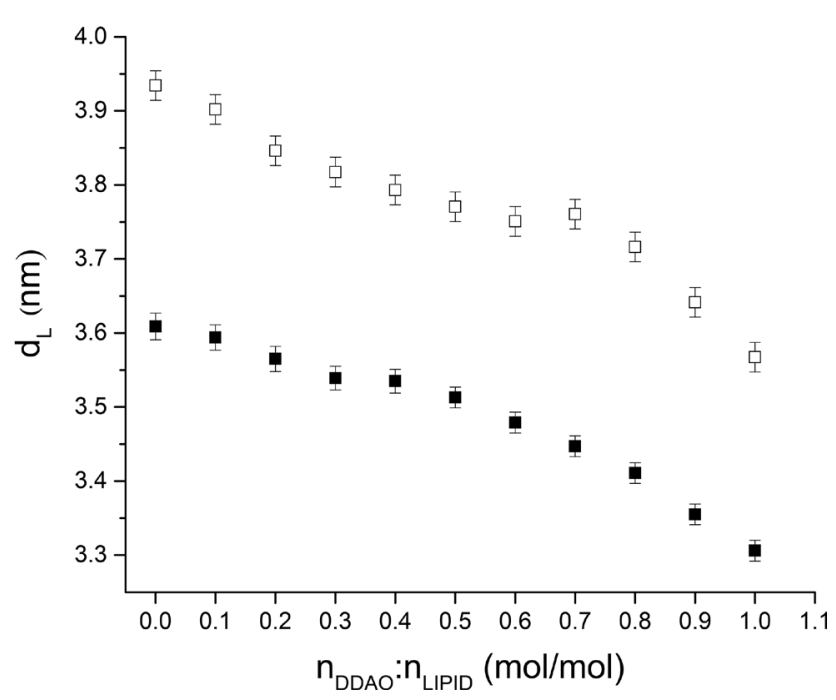

Figure 5. Bilayer thickness of liposomes consisting of DOPC (full squares) and DOPC-CHOL (empty squares) as a function of the molar ratio $\mathrm{n}_{\mathrm{DDAO}}: \mathrm{n}_{\mathrm{LIPID}}$. 
tering curve for DOPC in neat $\mathrm{D}_{2} \mathrm{O}$ showed an indication of aggregation after $24 \mathrm{~h}\left(\mathrm{~N}_{\mathrm{L}} \sim 1.3\right.$ when lamellar paracrystal model is used).

The agreement of the scattering curves and fits by lamellar paracrystal model, as measured by $\chi^{2}$, is in the range $2-3$ for low DDAO concentration. The coincidence is getting worse for $\mathrm{n}_{\mathrm{DDAO}}: \mathrm{n}_{\text {LIPID }} \geq 0.6$ and a lamellar paracrystal model is no more convenient for $\mathrm{n}_{\mathrm{DDAO}} \mathrm{n}_{\text {LIPID }}>1$.

The SANS data in the range $\mathrm{n}_{\mathrm{DDAO}}: \mathrm{n}_{\text {LIPID }}=3-5$ are analysed using a model of rigid cylinder with elliptical cross section with respect to the minor elliptical radius $R_{M I N}$, ratio of elliptical radii $v$ and cylinder length $\mathrm{L}$ distribution. Geometrical characteristics of cylindrical aggregates of DOPC-DDAO and DOPC-CHOL-DDAO are presented in Table 2 . Small values of $\chi^{2}$ corroborate a high coincidence of the fits with measured data. As an example, Figure 4 shows the best fit of experimental scattering curves at the molar ratio $\mathrm{n}_{\mathrm{DDAO}}: \mathrm{n}_{\text {LIPID }}=5$.

SANS data measured at high DDAO concentration were successfully fitted also using a model of flexible cylinder with elliptical cross section. The stiffness of the flexible cylinder is described by a Kuhn length $B=2 l_{p}$, where persistent length $l_{p}$ is the length along the cylinder over which the cylinder can be considered a rigid rod. Typical value of the ratio $\mathrm{L} / \mathrm{B}$ was around one and the uncertainty of the Kuhn length was very high (in several cases more than 50\%). The geometrical parameters of lipid aggregates presented in Table 2 were very similar for both models, rigid and flexible cylinder. The concord of experimental data and the fit was much worse if a model of cylinder with circular cross section was used.

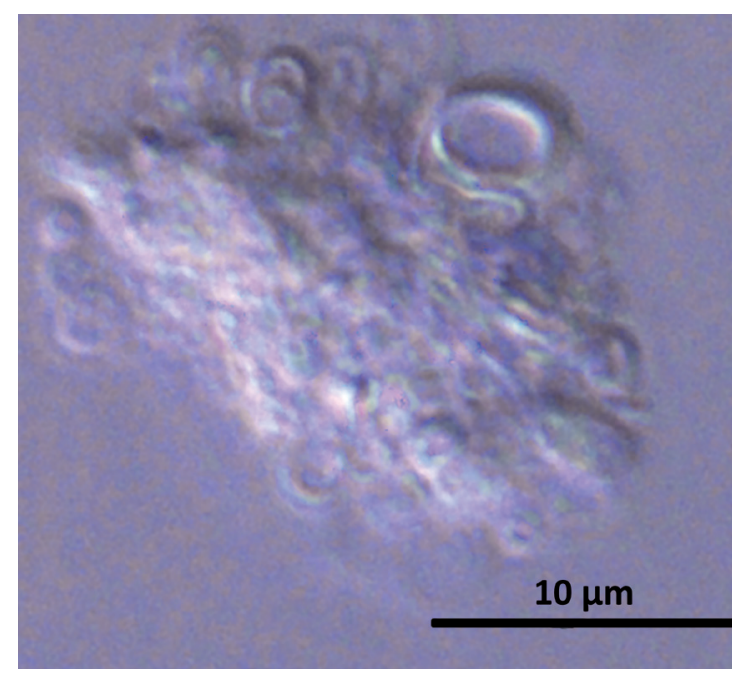

Figure 6. Aggregates of lipid structures present in the dispersion of extruded DOPC liposomes in PBS. Shot was taken using DIC microscopy technique. Microscope Nikon Eclipse TsR (Nikon, Japan) with PLAN FLUOR 100x Oil Ph3 DLL lens (1000x magnification) and a camera DS Fi2-U3 were used.
The cross-sectional dimensions of the DOPC-DDAO elliptical cylinders at $\mathrm{n}_{\mathrm{DDAO}}: \mathrm{n}_{\mathrm{DOPC}}=3$ are $3.52 \pm 0.02 \mathrm{~nm}$ $\left(2 \mathrm{R}_{\mathrm{MIN}}\right)$ and $6.3 \pm 0.02 \mathrm{~nm}\left(2 \mathrm{R}_{\mathrm{MAJOR}}\right.$, calculated using the ratio of elliptical radii $v$ ). The former value is similar to the thickness of DOPC-DDAO bilayer. This suggests that the central part of the particle is constituted by the DOPCDDAO bilayer and the edges are stabilised by DDAO, as illustrated in Figure 7.

As far as DOPC-CHOL-DDAO particles are concerned, solubilisation progressed in a similar way as we have observed for DOPC-DDAO particles. It can be seen from Table 2 that cylindrical micelles DOPC-DDAO and DOPCCHOL-DDAO differ in some geometrical parameters. At $\mathrm{n}_{\mathrm{DDAO}}: \mathrm{n}_{\mathrm{DOPC}+\mathrm{CHOL}}=3$ the particles with elliptical crosssectional dimensions $3.53 \pm 0.02 \mathrm{~nm}$ and $10.16 \pm 0.02 \mathrm{~nm}$ were observed. The thickness in the smaller half-axis of the ellipse is similar as in DOPC-DDAO, but the ellipse is more elongated in the direction of the longer half-axis. Cylinders containing CHOL are shorter. The length of cylinders of both compositions and ratio of elliptical radii decrease upon increasing DDAO concentration.

The data collected with DOPC aggregates are in agreement with the previous study of Uhríková et al. (2001), where bilayers or/and bilayer fragments have been observed up to $\mathrm{n}_{\mathrm{DDAO}}: \mathrm{n}_{\mathrm{DOPC}}=1.5$, rod-like particles (tubular, cylindrical micelles) at $2.5<\mathrm{n}_{\text {DDAO: }} \mathrm{n}_{\mathrm{DOPC}}<3.5$, and transition to globular particles (spheroid micelles) at $\mathrm{n}_{\mathrm{DDAO}}: \mathrm{n}_{\mathrm{DOPC}}>4$ using SANS. In the present work, using SANS, we were able to determine the dimensions of cylindrical micelles and to point out the tendency of aggregation of ULLs when physiological solution or PBS buffer is used instead of $\mathrm{D}_{2} \mathrm{O}$.

\section{Discussion}

In the present paper, we have studied interaction of model membranes composed of DOPC and DOPC enriched by CHOL with surfactant DDAO in a wide range of surfactant concentrations. The molar ratio of $\mathrm{PC}$ to $\mathrm{CHOL}=2: 1 \mathrm{~mol} /$ mol is typical for plasmatic mammalian membrane (Huang et al. 1999; Ohvo-Rekilä et al. 2002; Mouritsen and Zuckermann 2004). The maximum solubility of CHOL in PC bilayers is limited to $66 \mathrm{~mol} \%$ (Huang et al. 1999). The amount of CHOL used in our samples ( $33 \mathrm{~mol} \%$ ) is therefore completely soluble. The main phase transition temperature of DOPC in aqueous environment is $-17.3^{\circ} \mathrm{C}$ (Lewis et al. 1988). DOPC is therefore in liquid-disordered phase $\left(l_{\alpha}\right)$ at laboratory temperature. In the presence of $\geq 25 \mathrm{~mol} \%$ of $\mathrm{CHOL}$, a wide range of lipids create a liquid-ordered $\left(l_{\mathrm{o}}\right)$ phase with translational mobility of molecules similar as in $l_{\alpha}$ phase, but with high order of acyl chain segments. Model membrane comprised of DOPC and $33 \mathrm{~mol} \%$ of CHOL may 
consist of a uniform phase with properties between $l_{\alpha}$ and $l_{o}$ phase or by nanoscopic regions of $l_{\alpha}$ and $l_{o}$ phases (van Meer et al. 2009)

\section{Solubilisation}

Permeabilisation of DOPC and DOPC-CHOL bilayers was studied by leakage of calcein through pores in bilayer induced by surfactant DDAO. Effective ratio $R_{e}$ at the onset of massive leakage is around 0.6 in both model membranes (Tab. 1). To compare the activity of DDAO to permeabilise lipid membrane with other surfactants, Triton X-100 (TX100) causes practically instantaneous, complete leakage of EYPC vesicles at $\mathrm{R}_{\mathrm{e}} \sim 0.4$. Smaller surfactant concentrations cause leakage at slower rates.

Turbidimetry was used to follow changes in the size of lipid aggregates with increasing DDAO concentration. The turbidity is approximately stable in the first phase (at $\mathrm{c}_{\mathrm{DDAO}}<$ $\mathrm{D}_{\mathrm{t}}^{\mathrm{SAT}}$ ), when lipid bilayers are gradually saturated by the surfactant. The process of solubilisation follows the typical three-stage model, which enables the determination of critical DDAO concentrations required for the onset $\left(D_{t}{ }^{S A T}\right)$ and completion $\left(\mathrm{D}_{\mathrm{t}}^{\mathrm{SOL}}\right)$ of mixed micelles formation, as well as concentration needed to diminish the turbidity to $50 \%$ $\left(\mathrm{D}_{\mathrm{t}}^{\mathrm{MID}}\right)$. Critical concentrations obtained by turbidimetry and leakage experiments, measured at various lipid concentrations, allowed the establishment of parameters $R_{e}$ and $\mathrm{D}_{\mathrm{w}}$, along with the calculation of $\mathrm{K}_{\mathrm{p}}$ of DDAO between both model membranes and aqueous phase. Above $\mathrm{D}_{t}^{\mathrm{SAT}}$, upon further increase in surfactant concentration, large DOPCDDAO and DOPC-CHOL-DDAO liposomes disintegrate into smaller surfactant-lipid mixed micelles. As shown by SANS, these mixed micelles have the shape of cylinders with elliptical cross section. This shape evolves with increasing DDAO concentration towards smaller and more spherical micelles.

As concluded in Lichtenberg et al. (2013b), the contemporary paradigm is that during the bilayer to micelle phase transition, long thread-like mixed micelles are formed at first

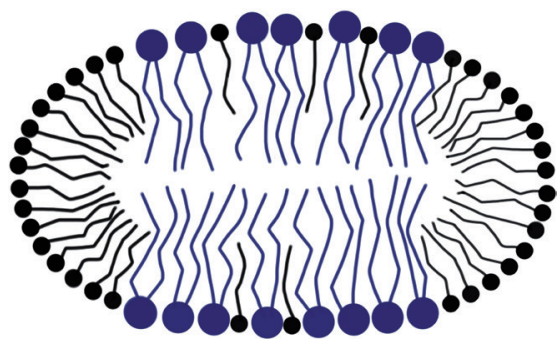

Figure 7. Schematic representation of elliptical cross section of the DOPC-DDAO cylinder. DOPC (two chains), DDAO (single chain).

and subsequent addition of surfactant results in the decrease of length of these micelles. This is supported by our data (Table 2). Cylindrical micelles in coexistence with bilayer sheets were observed e.g. by cryo-TEM after addition of nonionic surfactant $\mathrm{C}_{12} \mathrm{E}_{8}$ to EYPC ULLs dispersion (Edwards and Almgren 1991). A theoretical analysis (Fattal et al. 1995; Kozlov et al. 1997) suggested that the most probable aggregates resulting from interaction of phospholipid bilayer with micelle-forming surfactant are cylindrical micelles, which is consistent with our data. Author Almgren (2000) concluded in his study that in the case of non-ionic surfactants, rod-like or thread-like mixed micelles, with preserved composition of the bilayer, starts to form after reaching the saturation point. Appearance of cylindrical aggregates with elliptical cross section was theoretically predicted (Goltsov and Barsukov 2000) and experimentally observed (Kiselev et al. 2008) in binary mixture of dimyristoylphosphatidylcholine (DMPC) and sodium cholate.

\section{Partition coefficient}

We have determined partition coefficients of DDAO in a bilayer consisting of pure DOPC $\mathrm{K}_{\mathrm{p}}=2262 \pm 379$ and $\mathrm{K}_{\mathrm{p}}=2092$ \pm 594 for the membrane enriched in CHOL. Hrubšová et al. (2003) calculated the molar partition coefficient of DDAO

Table 2. Geometrical parameters of cylindrical aggregates of DOPC and DOPC-CHOL at high DDAO concentrations

\begin{tabular}{lccccc}
\hline Model membrane & $\mathrm{n}_{\text {DDAO: }} \mathrm{n}_{\text {LIPID }}$ & $\mathrm{R}_{\mathrm{MIN}}(\mathrm{nm})$ & $v$ & $\mathrm{~L}(\mathrm{~nm})$ & $\chi^{2}$ \\
\hline \multirow{3}{*}{ DOPC } & 3 & $1.76 \pm 0.01$ & $1.79 \pm 0.02$ & $521 \pm 75$ & 3.66 \\
& 4 & $1.67 \pm 0.01$ & $1.67 \pm 0.02$ & $37 \pm 1$ & 1.38 \\
& 5 & $1.67 \pm 0.01$ & $1.55 \pm 0.02$ & $18.6 \pm 0.3$ & 1.19 \\
\cline { 2 - 5 } DOPC-CHOL & 3 & $1.77 \pm 0.01$ & $2.87 \pm 0.03$ & $19.7 \pm 0.3$ & 1.94 \\
& 4 & $1.77 \pm 0.01$ & $2.04 \pm 0.02$ & $13.1 \pm 1.4$ & 1.65 \\
& 5 & $1.79 \pm 0.01$ & $1.70 \pm 0.03$ & $10.2 \pm 0.1$ & 0.63 \\
\hline
\end{tabular}

Elliptical cross section of the rigid cylinder is described by the minor radius $\mathrm{R}_{\mathrm{MIN}}$ and the ratio of elliptical radii $v, L$ is the length of cylinder. $\chi^{2}$ characterises the agreement of the fit with experimental data. 
between EYPC ULLs and water to be $K_{p}=507 \pm 215$, using the dependence of $\mathrm{D}_{\mathrm{t}}^{\mathrm{MID}}$ on the lipid concentration. The effective molar ratio $R_{e}$ for the $D_{t}$ MID concentration was $0.60 \pm 0.16$. In our case, more DDAO incorporated into the bilayer was needed to achieve this exact critical point of solubilisation, specifically, $2.20 \pm 0.25$ for DOPC and $1.82 \pm 0.31$ for DOPC-CHOL bilayers. In Hrubšová et al. (2003), a buffer was not used. According to our unpublished results, when concentration of DDAO increases from 0.05 $\mathrm{mmol} / \mathrm{dm}^{3}$ to $3 \mathrm{mmol} / \mathrm{dm}^{3}$ in a dispersion of ULLs of EYPC $\left(0.4 \mathrm{mmol} / \mathrm{dm}^{3}\right)$ prepared in water, $\mathrm{pH}$ changes from 6.4 to 7.0. Because $\mathrm{pK}$ value is $\sim 5$, a part of DDAO molecules is positively charged. This can cause different results in comparison with those presented in this paper. MLLs composed of EYPC were reported to have a molar partition coefficient of DDAO equal to $1241 \pm 364$ (again calculated using the $\mathrm{D}_{\mathrm{t}}{ }^{\mathrm{MID}}$ ) in Karlovská et al. (2004a). The author suggests that the differences in the curvature between MLLs and ULLs affect the partitioning. Buffered aqueous phase $(\mathrm{pH}=8)$ was used, but attainment of partitioning equilibrium of DDAO molecules in multilamellar system is not guaranteed. The comparison of the present paper with Karlovská et al. (2004a) and Hrubšová et al. (2003) shows that the partition coefficient of DDAO in PC bilayer is higher at higher $\mathrm{pH}$ when DDAO molecules are not charged. The value of molar partition coefficient of DDAO 4000 is presented in KraghHansen et al. (1998) for a dispersion of ULLs of sarcoplasmic reticulum lipids. Therefore, it can be concluded that partition coefficient of DDAO is sensitive to the lipid structure, as well as the type of a model membrane. The partition coefficients of TX-100, which is being frequently used in industry, and of an anionic dodecylbenzene sulphonate (SDBS) between EYPC ULLs and Hepes buffer were determined using derivative spectrophotometry (TX-100: $4128 \pm 706$, SDBS: $19380 \pm 4594)$ and fluorescence quenching (TX-100: 6337, SDBS: 23800) method in Marcelino et al. (2007). Higher $K_{p}$ of these surfactants predisposes them to accumulate more in the environment and subsequently to manifest their toxic effects on living cells.

In Figure 3 and Table 1 we use molar ratio $\mathrm{n}_{\mathrm{DDAO}} \mathrm{n}_{\mathrm{LIPID}}$ where $n_{D D A O}$ refers exactly to the total amount of DDAO in the sample $\left(n_{t}\right)$, not in the bilayer $\left(n_{b}\right)$. However, because of the high value of partition coefficient, large portion of DDAO in the sample is incorporated in the lipid bilayer. For example, if the molar ratio $\mathrm{n}_{\mathrm{DDAO}} \mathrm{n}_{\mathrm{LIPID}}$ in the sample is equal to 1 , the effective molar ratio $R_{e}=0.96$. According to Table $1, \mathrm{R}_{\mathrm{e}}$ is around 0.6 when the onset of massive leakage of calcein is observed. Simultaneously, the coincidence between scattering curves and lamellar paracrystal model fit is getting worse for $\mathrm{n}_{\mathrm{DDAO}}: \mathrm{n}_{\text {LIPID }} \geq 0.6$, because defects in the bilayer structure occur. SANS results show that lamellar structure is still present at $\mathrm{n}_{\text {DDAO }} \mathrm{n}_{\text {LIPID }}=1$ (Fig. 4). This is in agreement with the value of $\mathrm{R}_{\mathrm{e}} \mathrm{SAT}$ which is higher than 1 .
We were not able to fit the scattering curve at $\mathrm{n}_{\text {DDAO: }} \mathrm{n}_{\text {LIPID }}$ $=2$ using a single model of lipid aggregate because it is near to $\mathrm{R}_{\mathrm{e}}$ MID where bilayers exist together with micelles. Balgavý et al. (2007) calculated that effective molar ratio of $\mathrm{n}_{\text {DDAO }}: \mathrm{n}_{\text {LIPID }} \sim 2$ is needed to fulfil the theoretical value of effective packing parameter for DOPC-DDAO aggregate equal to 0.5 at the transition of bilayers to cylindrical micelles. At concentrations of DDAO above $\mathrm{D}_{\mathrm{t}}^{\mathrm{SOL}}$ all bilayer structures are disintegrated. This corresponds well with the high quality fit of SANS data with cylindrical model. It means that our turbidimetry, fluorescence spectroscopy and SANS results are consistent.

\section{Influence of $\mathrm{CHOL}$}

Our results show that the exchange of a part of DOPC molecules by CHOL, so that $\mathrm{n}_{\mathrm{DOPC}}: \mathrm{n}_{\mathrm{CHOL}}=2: 1 \mathrm{~mol} /$ mol, does not significantly affect $R_{e}$, nor $K_{p}$, which within the experimental error do not considerably differ for both types of model membrane (Tab. 1). Similar results were reported in several papers for non-ionic surfactant TX-100. For example, Inoue and Kitagawa (1976) studied changes in permeability of liposomes of EYPC, dicetyl phosphate (molar ratio 1:0.1) and different amounts of CHOL in the presence of TX-100. They found that EYPC:CHOL bilayers at molar ratio 1.5:1 behaved very much like those of pure phospholipid, while those at a 1:1 ratio were slightly less sensitive to the detergent. Nagawa and Regen (1991) observed insensitivity of TX-100 to the presence of CHOL in palmitooleoylphosphatidylcholine (POPC) liposomes at molar ratios POPC:CHOL $=4: 1,2: 1$ and 1:1 when leakage of fluorescent probe 5,6-carboxyfluorescein was followed. Ruiz et al. (1988) reported that at molar ratio EYPC:CHOL $=3: 1$ bilayer permeability and solubilisation induced by TX-100 is similar as for CHOL-free liposomes. At equimolar EYPC/ CHOL ratio, solubilisation by $\mathrm{TX}-100$ was observed to be more difficult, but the release of encapsulated content of liposomes required even less surfactant.

On the other hand, many papers have shown increased stability of liposomes towards surfactant in the presence of CHOL. In probe leakage study (Cócera et al. 2003), the authors assumed that the increasing concentration of CHOL in EYPC liposomes reduced linearly the activity of anionic surfactant sodium dodecylsulphate (SDS) and its affinity to the membrane. The increasing presence of CHOL in bilayers (studied range 10-30 mol\% of $\mathrm{CHOL}$ ) resulted in a progressive increase of the $\mathrm{R}_{\mathrm{e}}$ values and a progressive decrease of $\mathrm{K}_{\mathrm{p}}$. The effect of CHOL incorporation into POPC bilayers on the leakage of fluorescent probe 5,6-carboxyfluorescein from liposomes was investigated in Apel-Paz et al. (2005). CHOL have linearly increased the resistance of liposomes against SDS attack until $30 \mathrm{~mol} \%$ of CHOL was reached, the amount of CHOL higher than $30 \mathrm{~mol} \%$ had "toughen- 
ing effect" on the membrane. Study of Nagawa and Regen (1991) reported significantly reduced ability of 4 different membrane disrupting surfactants to release internal contents of EYPC and POPC liposomes containing > $33 \mathrm{~mol} \%$ of CHOL. Study of Mattei et al. (2015) shows changes in the ability of TX-100 to solubilise POPC and egg sphingomyelin (ESM) liposomes after the addition of $30 \mathrm{~mol} \%$ of CHOL. The liposomes became either partially (POPC+CHOL) or totally $(\mathrm{ESM}+\mathrm{CHOL})$ insoluble by TX-100. Tamba et al. (2004) reported that giant unilamellar liposomes (GULs) and large unilamellar liposomes (LULs) of lipids in liquidordered phase were stable and no leakage of internal contents occurs in the presence of TX-100, but another surfactant, octylglucoside, could easily break these membranes and induce internal contents leakage. Ahyayauch et al. (2010) studied unique behaviour of different surfactants, in terms of transmembrane lipid motions, permeabilisation and vesicle lysis/reassembly, and noted that all surfactants interact with the lipid bilayer differently, therefore, it is difficult to compare them. It is not surprising that there are some differences in the effect of these surfactants, because of their different structures. SDS is an anionic surfactant, whereas DDAO is uncharged at physiological $\mathrm{pH}$. TX100 , on the other hand, is a non-ionic surfactant, but with a different structure (4-(1,1,3,3-Tetramethylbutyl)phenylpolyethylene glycol).

In our earlier study (Huláková et al. 2015), it was concluded that more DDAO is needed to perturb and solubilise ULLs of EYPC when increasing amount of CHOL is added to EYPC bilayer (within the studied range $\mathrm{n}_{\mathrm{CHOL}}: \mathrm{n}_{\mathrm{EYPC}}$ $=0-0.8$ ). In that work, the concentration of phospholipid (EYPC) was kept constant and the amount of CHOL progressively increased. It means that the total lipid (EYPC+CHOL) molar concentration increased. Therefore, more surfactant was needed to solubilise larger membrane composed of more molecules. In the present work, the total number of lipid molecules was kept constant but every third DOPC molecule was substituted by CHOL. The critical concentrations of DDAO have not been considerably altered by this substitution, which consequently led to a not very significant change in $R_{e}$ and $K_{p}$ values.

\section{Aggregation of liposomes}

SANS results corroborate that DOPC and DOPC-CHOL at zero or low DDAO concentration are arranged in a bilayer structure in liposomes. In the presence of PBS buffer or physiological solution, a correlation peak was detected in SANS curves of samples prepared using either $50 \mathrm{~nm}$ filter or $100 \mathrm{~nm}$ and subsequently $50 \mathrm{~nm}$ filter during extrusion. Correlation peak was present in SANS curves measured $3 \mathrm{~h}$ and $24 \mathrm{~h}$ after extrusion. On the other hand, scattering curves without the correlation peak (indicating independent ULLs) were measured with DOPC liposomes in $\mathrm{D}_{2} \mathrm{O}$ prepared either using $50 \mathrm{~nm}$ filter (e.g. Uhríková et al. 2001; Belička et al. 2014b; this paper) or using $200 \mathrm{~nm}$ filter (9 times), $100 \mathrm{~nm}$ filter ( 9 times) and $50 \mathrm{~nm}$ filter (19 times) in Kučerka et al. (2007). In these experiments, measurements were performed in the scope of several hours after the extrusion. Our SANS results indicate that increased ionic strength of solvent can induce interaction between ULLs.

Turbidity around 0.1 is typical for DOPC liposomes at the concentration $0.4 \mathrm{mmol} / \mathrm{dm}^{3}$ extruded in water through 100 nm filter (Huláková et al. 2013, 2015). Typical value for MLL at the same concentration is around 0.8 (our unpublished results). The value of turbidity around 0.18 (Fig. 1, inset) was measured when DOPC liposomes were extruded through $100 \mathrm{~nm}$ and subsequently through $50 \mathrm{~nm}$ filter. Turbidity even increased after interaction with small amount of DDAO $\left(c_{D D A O} \leq 1 \mathrm{mmol} / \mathrm{dm}^{3}\right)$, but decreased to a value typical for liposomes extruded through $100 \mathrm{~nm}$ filter at $\mathrm{c}_{\mathrm{DDAO}}<\mathrm{D}_{\mathrm{t}}^{\mathrm{SAT}}$. Further solubilisation process is independent on the pore diameter of the filter used during the extrusion. This fact, together with the low value of interacting bilayers $\left(\mathrm{N}_{\mathrm{L}} \sim 1.4\right)$ found by SANS, indicate that aggregation of ULLs is more probable than a formation of oligolamellar liposomes.

Our SANS and turbidity experiments show that the aggregation of ULLs made of DOPC can be induced and influenced by several factors like ionic strength of the solute, $\mathrm{pH}$ (unpublished results), liposomes diameter, DOPC concentration and incubation time between liposome extrusion and measurement. Aggregation of ULLs was seen also by other authors, e.g. McConnell and Schullery (1985) for dipalmitoylphosphatidylcholine liposomes.

\section{Conclusion}

Solubilisation of DOPC and DOPC:CHOL $=2: 1(\mathrm{~mol} /$ mol) model membranes by non-charged surfactant DDAO ( $\mathrm{pH}$ 7.5) was researched. Pore formation in lipid bilayer was studied by fluorescence probe leakage method. The changes in the size of lipid aggregates upon increasing DDAO concentration were followed turbidimetrically. Effective ratio $R_{e}$ at various steps of the solubilisation process was determined. The molar partition coefficient of DDAO in case of the DOPC membrane is $\mathrm{K}_{\mathrm{p}}=2262 \pm 379$, for DOPC-CHOL membrane $\mathrm{K}_{\mathrm{p}}=2092 \pm 594$. Within the experimental error, the partition coefficient, as well as effective ratios $R_{e}$, are not considerably influenced when one third of DOPC molecules is substituted by CHOL. SANS, turbidity and microscopic results showed that liposomes of DOPC and DOPC-CHOL prepared in buffer $\left(50 \mathrm{mmol} / \mathrm{dm}^{3}\right.$ PBS, $150 \mathrm{mmol} / \mathrm{dm}^{3} \mathrm{NaCl}$ ) are prone to aggregate. After solubilisation of bilayer structures by surfactant, mixed 
DOPC-DDAO and DOPC-CHOL-DDAO cylinders with elliptical cross section were observed.

Acknowledgement. This work has been supported by the VEGA grants $1 / 0916 / 16$ and $1 / 0228 / 17$, JINR topical themes 04-4-11212015/2020 and APVV project 17-0239. This work benefited from the use of the SasView application, originally developed under NSF award DMR-0520547. SasView contains code developed with funding from the European Union's Horizon 2020 research and innovation programme under the SINE2020 project, grant agreement No 654000. Authors thank Norbert Kučerka for helpful discussion. K. Ž. and J. G. thank the staff of the Condensed Matter Division, Frank Laboratory of Neutron Physics, Joint Institute for Nuclear Research in Dubna (Russia), for the hospitality. J. G. and D. U. wish to thank prof. Pavol Balgavý for his long-standing inspiring guidance and friendship.

\section{References}

Ahyayauch H, Bennouna M, Alonso A, Goni FM (2010): Detergent effects on membranes at subsolubilizing concentrations: Transmembrane lipid motion, bilayer permeabilization, and vesicle lysis/reassembly are independent phenomena. Langmuir 26, 7307-7313

https://doi.org/10.1021/la904194a

Almgren M (2000): Mixed micelles and other structures in the solubilization of bilayer lipid membranes by surfactants. Biochim. Biophys. Acta 1508, 146-163 https://doi.org/10.1016/S0005-2736(00)00309-6

Alonso H, Roujeinikova A (2012): Characterization and two-dimensional crystallization of membrane component AlkB of the medium-chain alkane hydroxylase system from pseudomonas putida GPo1. Appl. Environ. Microbiol. 78, 7946-7953 https://doi.org/10.1128/AEM.02053-12

Apel-Paz M, Doncel GF, Vanderlick TK (2005): Impact of membrane cholesterol content on the resistance of vesicles to surfactant attack. Langmuir 21, 9843-9849 https://doi.org/10.1021/la050568r

Balgavý P, Šeršeň F, Leitmanová A, Devínsky F, Mlynarčík D (1989): The effect of N-(1-methyl-N-dodecyl)-N,N-dimethylaminoxide on the conformation of hydrocarbon chains in phospholipid bilayers isolated from E. coli. Biofizika 34, 814-818 (in Russian)

Balgavý P, Devínsky F (1996): Cut-off effects in biological activities of surfactants. Adv. Colloid Interface Sci. 66, 23-63 https://doi.org/10.1016/0001-8686(96)00295-3

Balgavý P, Devínsky F, Gallová J, Karlovská J, Kučerka N, Lacko I, Uhríková D (2007): Effects of surfactants on the structure of model membranes. In: Surfactants and Dispersed Systems in Theory and Practice. pp. 335-342, Polish Chemical Society, Wroclaw

Belička M, Klacsová M, Karlovská J, Westh P, Devínsky F, Balgavý P (2014a): Molecular and component volumes of N,N-dimethyl$\mathrm{N}$-alkylamine $\mathrm{N}$-oxides in DOPC bilayers. Chem. Phys. Lipids 180, $1-6$ https://doi.org/10.1016/j.chemphyslip.2014.02.007

Belička M, Kučerka N, Uhríková D, Islamov AK, Kuklin A, Devínsky F, Balgavý P (2014b): Effects of N,N-dimethyl-
$\mathrm{N}$-alkylamine-N-oxides on DOPC bilayers in unilamellar vesicles: Small-angle neutron scattering study. Eur. Biophys. J. 43, 179-189

https://doi.org/10.1007/s00249-014-0954-0

Benachir T, Lafleur M (1995): Study of vesicle leakage induced by melittin. Biochim. Biophys. Acta 1235, 452-460 https://doi.org/10.1016/0005-2736(95)80035-E

Bergström M, Pedersen JS, Schurtenberger P, Egelhaaf SU (1999): Small-angle neutron scattering (SANS) study of vesicles and lamellar sheets formed from mixtures of an anionic and a cationic surfactant. J. Phys. Chem. B 103, 9888-9897 https://doi.org/10.1021/jp991846w

Búcsi A, Karlovská J, Chovan M, Devínsky F, Uhríková D (2014): Determination of $\mathrm{pK}$ a of $\mathrm{N}$-alkyl-N,N-dimethylamine-Noxides using $1 \mathrm{H}$ NMR and 13C NMR spectroscopy. Chem. Pap. 68, 842-846 https://doi.org/10.2478/s11696-013-0517-3

Bukovský M, Mlynarčík D, Ondráčková V (1996): Immunomodulatory activity of amphiphilic antimicrobials on mouse macrophages. Int. J. Immunopharmacol. 18, 423-426 https://doi.org/10.1016/S0192-0561(96)00040-9

Chen Y, Qiao F, Fan Y, Han Y, Wang Y (2017): Interactions of phospholipid vesicles with cationic and anionic oligomeric surfactants. J. Phys. Chem. B 121, 7122-7132 https://doi.org/10.1021/acs.jpcb.7b05297

Cócera M, López O, Coderch L, Parra JL, de la Maza A (2003): Permeability investigations of phospholipid liposomes by adding cholesterol. Colloids Surfaces A Physicochem. Eng. Asp. 221, 9-17 https://doi.org/10.1016/S0927-7757(03)00104-3

de la Maza A, Parra JL (1994): Vesicle-micelle structural transition of phosphatidylcholine bilayers and Triton X-100. Biochem. J. 303, 907-914 https://doi.org/10.1042/bj3030907

de la Maza A, Lopez O, Coderch L, Parra JL (1998): Solubilization of phosphatidylcholine liposomes by the amphoteric surfactant dodecyl betaine. Chem. Phys. Lipids 94, 71-79 https://doi.org/10.1016/S0009-3084(98)00045-0

Devínsky F, Kopecká-Leitmanová A, Šeršeň F, Balgavý P (1990): Cut-off effect in antimicrobial activity and in membrane perturbation efficiency of the homologous series of N,Ndimethylalkylamine oxides. J. Pharm. Pharmacol. 42, 790-794 https://doi.org/10.1111/j.2042-7158.1990.tb07022.x

Doucet M, Cho JH, Alina G, Bakker J, Bouwman W, Butler P, Campbell K, Gonzales M, Heenan R, Jackson A, et al. (2017): SasView Version 4.1, http://www.sasview.org/

Dubničková M, Kiselev MA, Kutuzov S, Devínsky F, Gordeliy V, Balgavý P (1997): Effect of N-lauryl-N,N-dimethylamine Noxide on dimyristoyl phosphatidylcholine bilayer thickness: A small-angle neutron scattering study. Gen. Physiol. Biophys. 16, $175-188$

Edwards K, Almgren M (1991): Solubilization of lecithin vesicles by C12E8. J. Colloid Interface Sci. 147, 1-21 https://doi.org/10.1016/0021-9797(91)90129-V

Fattal DR, Andelman D, Ben-Shaul A (1995): The vesicle-micelle transiiion in mixed lipid-surfactant systems: a molecular model. Langmuir 11, 1154-1161 https://doi.org/10.1021/la00004a020 
Feigin LA, Svergun DI (1987): Structure Analysis by Small-Angle $\mathrm{X}$-Ray and Neutron Scattering. Plenum, New York https://doi.org/10.1007/978-1-4757-6624-0

Fukunaga E, Ohiwa Y, Yamada M, Sumi A, Satoh M, Oyama Y (2014) Effects of N,N-dimethyldodecylamine-N-oxide on some cellular parameters of rat thymocytes. Nat. Sci. Res. 28, 21-24

Gallová J, Uhríková D, Kučerka N, Teixeira J, Balgavý P (2010) Partial area of cholesterol in monounsaturated diacylphosphatidylcholine bilayers. Chem. Phys. Lipids 163, 765-770 https://doi.org/10.1016/j.chemphyslip.2010.08.002

Gallová J, Klacsová M, Devínsky F, Balgavý P (2015): Partial volumes of cholesterol and monounsaturated diacylphosphatidylcholines in mixed bilayers. Chem. Phys. Lipids 190, 1-8 https://doi.org/10.1016/j.chemphyslip.2015.06.001

Gandhavadi M, Allende D, Vidal A, Simon SA, McIntosh TJ (2002): Structure, composition, and peptide binding properties of detergent soluble bilayers and detergent resistant rafts. Biophys. J. 82, 1469-1482 https://doi.org/10.1016/S0006-3495(02)75501-X

Goltsov AN, Barsukov LI (2000): Synergetics of the membrane selfassembly: A micelle-to-vesicle transition. J. Biol. Phys. 26, 27-41 https://doi.org/10.1023/A:1005139631164

Goni FM, Alonso A (2000): Spectroscopic techniques in the study of membrane solubilization, reconstitution and permeabilization by detergents. Biochim. Biophys. Acta 1508, 51-68 https://doi.org/10.1016/S0304-4157(00)00011-3

Heerklotz H (2008): Interactions of surfactants with lipid membranes. Q. Rev. Biophys. 41, 205-264 https://doi.org/10.1017/S0033583508004721

Heerklotz H, Blume A (2012): Detergent interactions with lipid bilayers and membrane proteins. Comprehensive Biophysics 5, 63-91 https://doi.org/10.1016/B978-0-12-374920-8.00529-4

Helenius A, Simons K (1975): Solubilization of membranes by detergents. Biochim. Biophys. Acta 415, 29-79 https://doi.org/10.1016/0304-4157(75)90016-7

Herrmann KW (1962): Non-ionic-cationic micellar properties of dimethyldodecylamine oxide. J. Phys. Chem. 66, 295-300 https://doi.org/10.1021/j100808a025

Hrubšová A, Karlovská J, Devínsky F, Lacko I, Balgavý P (2003): Solubilization of unilamellar egg yolk phosphatidylcholine liposomes by $\mathrm{N}$-alkyl-N,N-dimethylamine $\mathrm{N}$-oxides. Česká a Slov. Farm. 52, 299-305 (in Slovak)

Huang J, Buboltz JT, Feigenson GW (1999): Maximum solubility of cholesterol in phosphatidylcholine and phosphatidylethanolamine bilayers. Biochim. Biophys. Acta 1417, 89-100 https://doi.org/10.1016/S0005-2736(98)00260-0

Hubčík L, Funari SS, Pullmannová P, Devínsky F, Uhríková D (2015): Stimuli responsive polymorphism of C12NO/DOPE/ DNA complexes: Effect of $\mathrm{pH}$, temperature and composition. Biochim. Biophys. Acta 1848, 1127-1138 https://doi.org/10.1016/j.bbamem.2015.01.020

Huláková S, Fulier B, Gallová J, Balgavý P (2013): Effect of N-dodecyl-N,N-dimethylamine $\mathrm{N}$-oxide on unilamellar liposomes. Acta Fac. Pharm. Univ. Comenianae 60, 7-13 https://doi.org/10.2478/afpuc-2013-0021

Huláková S, Gallová J, Devínsky F (2015): Cholesterol protects phosphatidylcholine liposomes from N,N-dimethyl-1-dodecanamine N-oxide influence. Acta Chim. Slov. 62, 420-427 https://doi.org/10.17344/acsi.2014.750

Inoue K, Kitagawa T (1976): Effect of lipid composition on senzitivity of lipids membranes to Triton X. Biochim. Biophys. Acta 426, 1-16 https://doi.org/10.1016/0005-2736(76)90424-7

Kacáni L, Ferencík M, Devínsky F, Dierich MP (1996): Immunomodulatory effect of some amphiphilic detergents on the human promyelocytic HL-60 cells. Folia Biol. (Prague) 42, 11-16

Karlovská J, Devínsky F, Lacko I, Gallová J, Balgavý P (2004a): Solubilization of multilamellar liposomes by N-dodecyl-N,Ndimethylamine $\mathrm{N}$-oxide. Acta Fac. Pharm. Univ. Comenianae 51, 119-128

Karlovská J, Lohner K, Degovics G, Lacko I, Devínsky F, Balgavý P (2004b): Effects of non-ionic surfactants N-alkyl-N,Ndimethylamine- $\mathrm{N}$-oxides on the structure of a phospholipid bilayer: Small-angle X-ray diffraction study. Chem. Phys. Lipids 129, 31-41 https://doi.org/10.1016/j.chemphyslip.2003.11.003

Kiselev MA, Lombardo D, Lesieur P, Kisselev AM, Borbely S, Simonova TN, Barsukov LI (2008): Membrane self assembly in mixed DMPC/NaC systems by SANS. Chem. Phys. 345, 173-180 https://doi.org/10.1016/j.chemphys.2007.09.034

Kozlov MM, Lichtenberg D, Andelman D (1997): Shape of phospholipid/surfactant mixed micelles: cylinders or disks? Theoretical analysis. J. Phys. Chem. B 101, 6600-6606 https://doi.org/10.1021/jp970295b

Kragh-Hansen U, le Maire M, Møller JV (1998): The mechanism of detergent solubilization of liposomes and protein-containing membranes. Biophys. J. 75, 2932-46 https://doi.org/10.1016/S0006-3495(98)77735-5

Kučerka N, Tristram-Nagle S, Nagle JF (2005): Structure of fully hydrated fluid phase lipid bilayers with monounsaturated chains. J. Membr. Biol. 208, 193-202 https://doi.org/10.1007/s00232-005-7006-8

Kučerka N, Pencer J, Nieh MP, Katsaras J (2007): Influence of cholesterol on the bilayer properties of monounsaturated phosphatidylcholine unilamellar vesicles. Eur. Phys. J. E Soft Matter 23, 247-254 https://doi.org/10.1140/epje/i2007-10202-8

Kuklin AI, Rogachev AV, Soloviov DV, Ivankov O, Kovalev YS, Utrobin PK, Kutuzov S, Soloviev AG, Rulev MI, Gordeliy VI (2017): Neutronographic investigations of supramolecular structures on upgraded small-angle spectrometer YuMO. J. Phys. Conf. Ser. 848, 1-18 https://doi.org/10.1088/1742-6596/848/1/012010

le Maire M, Champeil P, Møller JV (2000): Interaction of membrane proteins and lipids with solubilizing detergents. Biochim. Biophys. Acta 1508, 86-111 https://doi.org/10.1016/S0304-4157(00)00010-1

Lewis R, Sykes BD, McElhaney RN (1988): Thermotropic phase behavior of model membranes composed of phosphatidylcholines containing cis-monounsaturated acyl chain homologues of oleic acid: differential scanning calorimetric and 31P NMR spectroscopic studies. Biochemistry 27, 880-887 https://doi.org/10.1021/bi00403a007

Lichtenberg D (1985): Characterization of the solubilization of lipid bilayers by surfactants. Biochim. Biophys. Acta 821, 470-478 
https://doi.org/10.1016/0005-2736(85)90052-5

Lichtenberg D, Ahyayauch H, Alonso A, Goni FM (2013a): Detergent solubilization of lipid bilayers: A balance of driving forces. Trends Biochem. Sci. 38, 85-93

https://doi.org/10.1016/j.tibs.2012.11.005

Lichtenberg D, Ahyayauch H, Goni FM (2013b): The mechanism of detergent solubilization of lipid bilayers. Biophys. J. 105, 289-299 https://doi.org/10.1016/j.bpj.2013.06.007

Liskayová G, Hubčík L, Šišková K, Pauliková I, Galliková D, Devínsky F, Funari SS, Uhríková D (2017): PH-sensitive N,N(dimethyl)- $\mathrm{N}$-alkanamine- $\mathrm{N}$-oxides as gene delivery vectors. Chem. Pap. 71, 1739-1748

https://doi.org/10.1007/s11696-017-0171-2

MacDonald RC, MacDonald RI, Menco BPM, Takeshita K, Subbarao NK, Hu LR (1991): Small-volume extrusion apparatus for preparation of large, unilamellar vesicles. Biochim. Biophys. Acta 1061, 297-303 https://doi.org/10.1016/0005-2736(91)90295-J

Marcelino J, Lima JLFC, Reis S, Matos C (2007): Assessing the effects of surfactants on the physical properties of liposome membranes. Chem. Phys. Lipids 146, 94-103 https://doi.org/10.1016/j.chemphyslip.2006.12.008

Mattei B, Franca ADC, Riske KA (2015): Solubilization of binary lipid mixtures by the detergent triton X-100: The role of cholesterol. Langmuir 31, 378-386 https://doi.org/10.1021/la504004r

McConnell DS, Schullery SE (1985): Phospholipid vesicle fusion and drug loading: temperature, solute and cholesterol effects, and, a rapid preparation for solute-loaded vesicles. Biochim. Biophys. Acta 818, 13-22 https://doi.org/10.1016/0005-2736(85)90132-4

Memoli A, Annesini MC, Petralito S (1999): Surfactant-induced leakage from liposomes: A comparison among different lecithin vesicles. Int. J. Pharm. 184, 227-235 https://doi.org/10.1016/S0378-5173(99)00105-2

Mouritsen OG, Zuckermann MJ (2004): What's so special about cholesterol? Lipids 39, 1101-1113 https://doi.org/10.1007/s11745-004-1336-x

Murín A, Devínsky F, Koleková A, Lacko I (1990): Relation between chemical-structure and biological-activity of $\mathrm{N}$-alkyl dimethylaminoxides series and some other related-compounds. Biologia 45, 521-531

Nagawa Y, Regen SL (1991): Membrane-disrupting surfactants that are highly selective toward lipid bilayers of varying cholesterol content. J. Am. Chem. Soc. 113, 7237-7240 https://doi.org/10.1021/ja00019a022

Nagle JF, Tristram-Nagle S (2000): Structure of lipid bilayers. Biochim. Biophys. Acta 1469, 159-195 https://doi.org/10.1016/S0304-4157(00)00016-2

Ohvo-Rekilä H, Ramstedt B, Leppimäki P, Slotte JP (2002): Cholesterol interactions with phospholipids in membranes. Prog. Lipid Res. 41, 66-97 https://doi.org/10.1016/S0163-7827(01)00020-0

Olson F, Hunt CA, Szoka FC, Vail WJ, Papahadjopoulos D (1979): Preparation of liposomes of defined size distribution by extru- sion through polycarbonate membranes. Biochim. Biophys. Acta 557, 9-23 https://doi.org/10.1016/0005-2736(79)90085-3

Partearroyo MA, Urbaneja MA, Goni FM (1992): Effective detergent/lipid ratios in the solubilization of phosphatidylcholine vesicles by Triton X-100. FEBS Lett. 302, 138-140 https://doi.org/10.1016/0014-5793(92)80424-F

Pedersen JS (1997): Analysis of small-angle scattering data from colloids and polymer solutions: modeling and least-squares fitting. Adv. Colloid Interface Sci. 70, 171-210 https://doi.org/10.1016/S0001-8686(97)00312-6

Pullmannová P, Bastos M, Bai G, Funari SS, Lacko I, Devínsky F, Teixeira J, Uhríková D (2012): The ionic strength effect on the DNA complexation by DOPC-gemini surfactants liposomes. Biophys. Chem. 160, 35-45 https://doi.org/10.1016/j.bpc.2011.09.002

Rigaud JL, Chami M, Lambert O, Levy D, Ranck JL (2000): Use of detergents in two-dimensional crystallization of membrane proteins. Biochim. Biophys. Acta 1508, 112-128 https://doi.org/10.1016/S0005-2736(00)00307-2

Ruiz J, Goni FM, Alonso A (1988): Surfactant-induced release of liposomal contents. A survey of methods and results. Biochim. Biophys. Acta 937, 127-134 https://doi.org/10.1016/0005-2736(88)90234-9

Šeršeň F, Gabunia G, Krejčírová E, Králová K (1992): The relationship between lipophilicity of $\mathrm{N}$-alkyl-N,N-dimethylamine oxides and their effects on the thylakoid membranes of chloroplasts. Photosynthetica 26, 205-212

Singh SK, Bajpai M, Tyagi VK (2006): Amine Oxides: A Review. J. Oleo Sci. 55, 99-119 https://doi.org/10.5650/jos.55.99

Soloviev AG, Solovjeva TM, Ivankov O, Soloviov DV, Rogachev AV, Kuklin AI (2017): SAS program for two-detector system: seamless curve from both detectors. J. Phys. Conf. Ser. 848, 1-7 https://doi.org/10.1088/1742-6596/848/1/012020

Tamba Y, Tanaka T, Yahagi T, Yamashita Y, Yamazaki M (2004): Stability of giant unilamellar vesicles and large unilamellar vesicles of liquid-ordered phase membranes in the presence of Triton X-100. Biochim. Biophys. Acta 1667, 1-6 https://doi.org/10.1016/j.bbamem.2004.09.004

Toro C, Sanchez SA, Zanocco A, Lemp E, Gratton E, Gunther G (2009): Solubilization of lipid bilayers by myristyl sucrose ester: effect of cholesterol and phospholipid head group size. Chem. Phys. Lipids 157, 104-112 https://doi.org/10.1016/j.chemphyslip.2008.11.004

Uhríková D, Kučerka N, Islamov A, Gordeliy V, Balgavý P (2001): Small-angle neutron scattering study of N-dodecyl-N,N-dimethylamine $\mathrm{N}$-oxide induced solubilization of dioleoylphosphatidylcholine bilayers in liposomes. Gen. Physiol. Biophys. 20, 183-189

van Meer G, Voelker DR, Feigenson GW (2009): Membrane lipids: where they are and how they behave. Nat. Rev. Mol. Cell Biol. 9, 112-124 https://doi.org/10.1038/nrm2330

Received: May 9, 2019

Final version accepted: November 21, 2019 